\title{
Slow- and Fast-Moving Information Content of CDS Spreads: New Endogenous Systematic Factors
}

\author{
Ming-Tsung Lin, Olga Kolokolova, Ser-Huang Poon*
}

September 4, 2019

\begin{abstract}
This paper proposes two new Credit Default Swap (CDS) endogenous systematic factors constructed from peer-CDS information. The factors capture slow-moving credit risk information, as well as fast-moving newly arrived market information embedded in the most recent CDS quotes. Using a sample of U.S. non-financial listed firms from 2002 to 2011, we find that these two endogenous systematic factors dominate firm-specific factors and other widely known systematic factors in insample and out-of-sample CDS spread predictions.
\end{abstract}

Key words: CDS spread, credit risk, liquidity risk, systematic factors JEL: G13, G23

\footnotetext{
*Ming-Tsung Lin (ming-tsung.lin@dmu.ac.uk) is at the De Montfort University, UK; Olga Kolokolova (olga.kolokolova@manchester.ac.uk) and Ser-Huang Poon (ser-huang.poon@manchester.ac.uk) are at the University of Manchester, Alliance Manchester Business School, UK.
} 


\title{
Slow- and Fast-Moving Information Content of CDS Spreads: New Endogenous Systematic Factors
}

\begin{abstract}
This paper proposes two new Credit Default Swap (CDS) endogenous systematic factors constructed from peer-CDS information. The factors capture slow-moving credit risk information, as well as fast-moving newly arrived market information embedded in the most recent CDS quotes. Using a sample of U.S. non-financial listed firms from 2002 to 2011, we find that these two endogenous systematic factors dominate firm-specific factors and other widely known systematic factors in in-sample and out-of-sample CDS spread predictions.
\end{abstract}

Key Words: CDS spread, credit risk, liquidity risk, systematic factors

JEL: G13, G23 


\section{Introduction}

Basel III stipulates that Credit Default Swap (CDS) implied default probability must be used in the calculation of risk capital attributed to counterparty credit risk. ${ }^{1}$ CDS is a credit derivative that offers protection against bond default. CDS prices are affected by the credit quality of the underlying, the firm default risk, as well as the CDS's liquidity risk, as shown empirically in, for example, Tang and Yan (2007) and Corò, Dufour, and Varotto (2013).

CDS is also used as a hedging tool for the underlying stock or bond, and vice versa, leading to interlocking relationships between these three markets. Doshi, Ericsson, Jacobs, and Turnbull (2013) show that bond market conditions affect CDS spreads. Norden and Weber (2009) examine the co-movements among stock, bond, and CDS markets, and find that CDS spread is sensitive to stock market information. Hammoudeh, Bhar, and Liu (2013) study the CDS indices of three financial sectors (i.e. banking, financial services, and insurance sectors), and find these three indices are interrelated to each other, leading to the risk of contagion across these sectors. All these studies also suggest the existence of some systematic pricing factors for CDS spreads that are endogenously embedded in these related markets. The focus of Hammoudeh, Bhar, and Liu (2013) is on financial sector CDS indices; our study covers individual CDS spreads of non-financial firms.

To complement the above literature, our paper explores a new set of CDS drivers, namely two endogenous systematic risk factors derived from individual firms' CDS spreads; capturing slow- and fast-moving information affecting CDS spreads. While deriving these two factors from CDS spreads, we control for the estimation error to increase the informativeness of the two factors. Using the 5-year CDS spreads for a sample of U.S. non-financial firms, we show that these new factors alone capture $22 \%$ of the monthly variations in the individual CDS spreads, while individual firm-specific factors and individual illiquidity

\footnotetext{
1 "[When computing CVA (Credit Valuation Adjustment) risk capital charge,] $s$ is the credit spread of the counterparty [...]. Whenever the CDS spread of the counterparty is available, this must be used. Whenever such a CDS spread is not available, the bank must use a proxy spread that is appropriate based on the rating, industry and region of the counterparty." Basel III: A global regulatory framework for more resilient banks and banking systems, p.32, http://www.bis.org/publ/bcbs189.pdf, (Basel Committee 2010).
} 
measure only explain $11 \%$ and $6 \%$, respectively, of the monthly variations. Moreover, in the presence of these new endogenous systematic factors, other previously suggested systematic factors such as VIX and term spread are no longer significant determinants of changes in CDS spreads.

In this paper, we use a CreditGrades (CG) model to price CDS, and run error-invariable regressions to control for model estimation error. We find that the CG model captures the credit information embedded in the CDS prices rather well, and the crosssectional average model spread adjusted for the estimation error thus constitutes our first endogenous factor representing the slow-moving systematic credit-risk factor.

The CDS market is less transparent than the equity market. CDSs are traded over the counter with considerable insider information, where the major participants are financial institutions (banks) and hedge funds (see. e.g., Acharya and Johnson 2007 and Bongaerts, Jong, and Driessen 2011). Thus, CDS quotes reflect new, possibly private, fast changing market information not captured by the slow-moving systematic creditrisk factor. The CDS quotes can reflect, for example, the latest news on the firm credit quality, the expectations of the overall market performance, and the current supply and demand for credit protection. We construct our second endogenous systematic factor as the cross-sectional average of the absolute difference between the observed CDS spread and its fitted value from the CG model, all adjusted for estimation errors. This factor could potentially capture all the new systematic information not already incorporated into firms' latest financial statements and historical volatilities. As market CDS spread responds to market news in a timely fashion, we label the factor constructed from daily CDS spread the "fast-moving" factor. While Corò, Dufour, and Varotto (2013) and Tang and Yan (2007) find CDS illiquidity to affect individual CDS spreads, CDS illiquidity only explains $4 \%$ of the changes of our fast-moving factor. As suggested by Collin-Dufresn, Goldstein, and Martin (2001), there exists an unexplained systematic component in the monthly changes of credit spreads of the industrial bonds, which is not related to commonly known determinants of credit spreads. 
The two endogenous CDS systematic factors proposed in our paper are more powerful in predicting changes in CDS spreads than all other commonly used systematic factors for both in-sample and out-of-sample predictions.

\section{Related literature}

Our paper contributes to the extensive literature on corporate credit and default risk, and the determinants of CDS spreads. This literature starts with Merton (1974)option pricing representation of a firm's default, which was later augmented by more complex creditor-shareholder interactions, e.g., strategic default in Leland and Toft (1996), creditor-shareholder bargaining in Fan and Sundaresan (2000), or stochastic jumps in Zhang, Zhou, and Zhu (2009)). Finger, Finkelstein, Lardy, Pan, Ta, and Tierney (2002) relax many assumptions in Merton (1974) and propose a CreditGrades (CG) model for CDS pricing, which we adopt in this paper.

The CDS market, being OTC, is more prone to market frictions and deviating from model predictions. Blanco, Brennan, and Marsh (2005), Ericsson, Jacobs, and Oviedo (2009), and Ericsson, Reneby, and Wang (2015) use structural models and find the existence of a non-credit related component in CDS spread, which they link to illiquidity. Ericsson, Jacobs, and Oviedo (2009), in particular, find that only asset volatility and leverage have strong effects on CDS spreads. Eom, Helwege, and Huang (2004) and Bao and Pan (2013) challenge the accuracy of the structural model, and find that structural models tend to underestimate default risk. Bedendo, Cathcart, and El-Jahel (2011) find the deviations of actual CDS prices from model prices to be related to liquidity the persistence of deviations suggests possible model mis-specification. Corò, Dufour, and Varotto (2013) find that the bid-ask spreads of intra-day CDS trades dominate other credit risk factors in explaining the CDS spreads for 135 European entities. Tang and Yan (2007) examine trade-to-quote ratio and bid-ask spread of CDS trades, and report a positive effect of these illiquidity measures on CDS spreads. 
Most studies construct CDS liquidity measures based on daily bid-ask spreads or intraday trading data (see Corò, Dufour, and Varotto 2013). Since we do not have bid-ask spreads for our sample, we have to explore other illiquidity measures. ${ }^{2}$ Goyenko, Holden, and Trzcinka (2009) find that low-frequency liquidity measures can capture the highfrequency liquidity effect in the stock market. Extending their findings to CDS market, we will use several low-frequency illiquidity measures as controls in all our regressions.

Cespa and Foucault (2014) extend the model of Gennotte and Leland (1990) and argue that illiquidity interacts between markets, affecting the equilibrium asset prices in different markets. Such a "cross-learning" forms a feedback loop between assets according to the level of price informativeness, and could lead to illiquidity spillover across markets. This corresponds to, for example, Das and Hanouna (2009) and Huang, Huang, and Oxman (2015), who find a linkage between equity and CDS markets. Das and Hanouna (2009) find stock illiquidity can explain the changes in the individual CDS spreads, which they argue is due to traders reverting to equity markets to hedge their exposure to credit risk. Similarly, Huang, Huang, and Oxman (2015) find that stock illiquidity increases CDS credit risk premium.

Arora, Gandhi, and Longstaff (2012) highlight the importance of the counterparty risk of the CDS provider. CDS spreads decrease as this risk rises, as the protection becomes less valuable when the ability of the CDS provider to offer protection diminishes. Chen, Chen, Sun, Yu, and Zhong (2013) document that credit risk insurers, who provide financial guarantee and write CDS contracts, were severely hit during the breakdown of the financial markets in 2007-2009. This created a profound effect on individual firm CDS spread.

Market-wide credit and liquidity shocks affect credit risk of firms (see, e.g., Almeida and Philippon 2007 and Jorion and Zhang 2009). We call these exogenous market factors for individual firm's CDS spreads. Doshi, Ericsson, Jacobs, and Turnbull (2013) show

\footnotetext{
${ }^{2}$ Our Markit database contains CDS spreads expressed as composite prices, where no bid and ask information is provided. Other CDS databases, such as Reuters EOD, and Credit Market Analysis (CMA), also provide composite prices for CDS. See Mayordomo, Peña, and Schwartz (2014) for a comprehensive comparison of those databases.
} 
that market variables, including 6-month Treasury yield and the difference between the 10-year and 6-month yields, explain cross-sectional CDS variations. Others reported a CDS "peer" effect; e.g., Conrad, Dittmar, and Hameed (2011) find that changes in the CDS spreads of the systematically important financial institutions lead the changes in the CDS spreads of other firms. Galil, Shapir, Amiram, and Ben-Zion (2014) find that the median CDS spreads of mixed credit quality have a cross-sectional explanatory power for individual firm's CDS spreads. For sovereign CDS, Longstaff, Pan, Pedersen, and Singleton (2011) show that global factors are more important than country factors in explaining sovereign CDS spread changes.

\section{Methodology}

Cespa and Foucault (2014) suggest that the price of an asset can be affected by prices of other (related) assets. Since CDS contracts are traded over the counter, the price formation process is less transparent, compared with other exchange-traded products. Thus, we may expect that peer information (i.e. price movement of other CDSs) will be more important as compared to, say, equity or bond markets. Previous studies of CDS systematic risk mainly focus, however, on co-movements with other financial markets (e.g. Norden and Weber 2009 and Doshi, Ericsson, Jacobs, and Turnbull 2013). Studies on systematic risk within CDS market are rather few, one example being Galil, Shapir, Amiram, and Ben-Zion (2014).

In this section, we propose two new endogenous CDS market systematic factors - the slow-moving credit factor and the fast-moving CDS-market uncertainty factor. We then present the regression specification to evaluate their relevance for the CDS pricing.

\subsection{The credit component of CDS spreads}

Every observed CDS spread can be decomposed into a credit-model fitted component and a residual, which may capture market liquidity, supply and demand for protection, and 
other price relevant news, which may be firm specific or systematic.

We choose the CreditGrades (CG) model, an extended Merton (1974) model, to calculate the credit component of individual CDS spreads. The CG model is developed collaboratively by Goldman Sachs, JPMorgan, RiskMetircs, and Deutsche Bank. The model has been widely used in industry since its introduction in May 2002, and has been endorsed by the largest dealers in credit markets. A full derivation of the model is in Finger, Finkelstein, Lardy, Pan, Ta, and Tierney (2002). The empirical performance of the CG model is analyzed in Stamicar and Finger (2006), Yu (2006), and Bedendo, Cathcart, and El-Jahel (2011). Below we briefly describe the CG model and the computation of the model-implied CDS spread.

In the CG model, the firm's asset value per share $(V)$ evolves as a geometric Brownian motion as follows:

$$
\frac{d V_{t}}{V_{t}}=\sigma d W_{t}
$$

where $W$ is standard Brownian motion and $\sigma$ is the asset volatility. The firm's debt value per share, denoted by $D$, is assumed to be constant, but the global recovery rate, denoted by $L$, is log-normally distributed with mean $\bar{L}$ and standard deviation $\lambda$. Therefore, the default barrier, the product of $L$ and $D$, is a random variable:

$$
L D=\bar{L} D e^{\lambda Z-\lambda^{2} / 2}
$$

where $Z$ is a standard Normal random variable, independent of $W$. In Merton (1974), the default barrier is just a constant $D$. Under the CG model, the firm does not default at time $t$ if its asset value is larger than the default barrier, i.e. $V_{0} e^{\sigma W_{t}-\sigma^{2} t / 2}>\bar{L} D e^{\lambda Z-\lambda^{2} / 2}$, where $V_{0}$ is the firm's initial asset value per share at time $t_{0}$. Under the first passage time framework, the survival probability at time $t$, denoted by $P(t)$, can be computed by:

$$
P(t)=\Phi\left(-\frac{A_{t}}{2}+\frac{\log (d)}{A_{t}}\right)-d \times \Phi\left(-\frac{A_{t}}{2}-\frac{\log (d)}{A_{t}}\right)
$$


where

$$
d=\frac{V_{0} e^{\lambda^{2}}}{\bar{L} D} \text { and } A_{t}^{2}=\sigma^{2} t+\lambda^{2}
$$

and $\Phi$ is the standard Normal cumulative distribution function (CDF).

The value of CDS spread can be calculated once the survival probability is determined. Consider a CDS contract with maturity $t$, the CDS spread, $c$, can be determined by:

$$
(1-R)\left[1-P(0)+\int_{0}^{t} d s f(s) e^{-r s}\right]=c \int_{0}^{t} d s e^{-r s} P(s)
$$

where $r$ is the risk-free rate, $R$ is the recovery rate, $P(\cdot)$ is the survival probability, and $f(\cdot)$ is the probability density function (pdf) for $P(\cdot)$, defined as $f(t)=-d P(t) / d t$. The left-hand side of the equation is the CDS seller's expectation in present value, while the right-hand side is the CDS buyer's expectation in present value.

Substituting $P(\cdot)$ from Equation (3), $c$ can be determined by:

$$
\begin{aligned}
c & =C G \operatorname{Spread}(V, D, R, \sigma, \lambda, \bar{L}, r, t) \\
& =r(1-R) \frac{1-P(0)+e^{r \zeta}(G(t+\zeta)-G(\zeta)}{P(0)-P(t) e^{-r t}-e^{r \zeta}(G(t+\zeta)-G(\zeta))},
\end{aligned}
$$

where

$$
\begin{aligned}
\zeta & =\lambda^{2} / \sigma^{2}, \text { and } \\
G(u) & =d^{z+0.5} \Phi\left(-\frac{\log (d)}{\sigma \sqrt{u}}-z \sigma \sqrt{u}\right)+d^{-z+0.5} \Phi\left(-\frac{\log (d)}{\sigma \sqrt{u}}+z \sigma \sqrt{u}\right) \\
\text { with } z & =\sqrt{0.25+2 r \sigma^{-2}} .
\end{aligned}
$$

Following Finger et al. (2002), we set $\bar{L}$ and $R$ both as $0.5, \lambda$ as 0.3 , and $r$ as the (5year) swap rate. Debt per share is calculated as Total Liability / Outstanding Common Shares. Asset value per share is calculated as $S+\bar{L} D$, where $S$ is share price. Asset volatility, $\sigma$, is calculated as $\sigma_{s} \times \frac{S}{S+\bar{L} D}$, where $\sigma_{s}$ is the stock volatility over the past year. The model CDS spread (denoted by CGSpread) is computed for all firms in our sample 
every month. We adjust the model CDS spread for estimation errors (the procedure is detailed in Section 3.2 to obtain the error adjusted model spread CGSpread ${ }_{i, t}^{*}$ for each firm $i$ and month $t$.

We construct our first endogenous systematic CDS factor as the cross-sectional averages of the natural logarithms of the CGSpread ${ }_{i, t}^{*}$ :

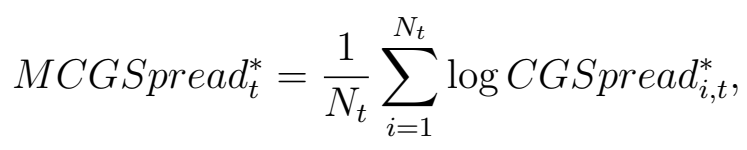

where $N_{t}$ is the number of available CDS observations at time $t$.

The key drivers of CGSpread ${ }_{i, t}^{*}$ are recent accounting data (in particular, the amount of debt per share), the current share price, as well as stock return volatility estimated using daily stock returns over the previous year. Firm debt and stock return volatility are both known to be fairly persistent (see, e.g., Lemmon, Roberts, and Zender (2008) and Hanousek and Shamshur (2011) for leverage persistence, and Chou (1988) and Choi and Richardson (2016) for volatility persistence), making CGSpread ${ }_{i, t}^{*}$ and its cross-sectional average MCGSpread ${ }_{t}^{*}$ intrinsically persistent, slow moving. In reality, both leverage and volatility can change abruptly and frequently. However, the former can be detected only after the release of quarterly financial statements; and the latter requires a one-year estimation horizon, i.e., a sufficient number of daily observations from the new volatility regime are needed to change the estimate. Hence, MCGSpread w $_{t}^{*}$ will always be slow moving due to general persistence of its drivers, and also due to the frequency of accounting information releases and data requirements for the reliable estimation of the volatility.

\subsection{The uncertainty component of CDS spreads}

To understand the extent to which the CG model can explain the actual CDS spreads, one could estimate a pooled panel OLS regression as follows:

$$
\text { Spread }_{i, t}=\alpha+\beta C G \text { Spread }_{i, t}+\varepsilon_{i, t} .
$$


If the actual CDS spread is fully captured by the CG model, we should get $\alpha=0$ and $\beta=1$.

CGSpread C $_{i, t}$ calculated according to Equation (5) is likely to suffer from an estimation error (denoted as $\eta$ ), i.e., CGSpread $=C G S p r e a d^{*}+\eta$, where CGSpread ${ }^{*}$ is the model error adjusted CG-Spread. Ideally, one should test Equation (7) using the model error adjusted CGSpread* ${ }^{*}$ To address this issue, we perform the Deming (1943) total least squares (TLS). TLS regression is a type of error-in-variable regression, under which the independent variable $x$ and dependent variable $y$ are assumed to have estimation error:

$$
y=y^{*}+\varepsilon \text { and } x=x^{*}+\eta
$$

where $y^{*}$ and $x^{*}$ are the true values and $\varepsilon$ and $\eta$ are the residuals. Assuming that $x^{*}$ and $y^{*}$ are in a linear relation of the form $y^{*}=\alpha+\beta x^{*}$, the the coefficients $\alpha$ and $\beta$ can be computed by:

$$
\begin{aligned}
& \beta=\frac{s_{y}^{2}-\delta s_{x}^{2}+\sqrt{\left(s_{y}^{2}-\delta s_{x}^{2}\right)^{2}+4 \delta s_{x y}^{2}}}{2 s_{x y}}, \\
& \alpha=\bar{y}-\beta \bar{x}
\end{aligned}
$$

where $\delta$ is the variance ratio $\sigma_{\varepsilon}^{2} / \sigma_{\eta}^{2}$, set as $1 . \bar{y}(\bar{x})$ is the sample mean. $s_{x}^{2}, s_{y}^{2}$, and $s_{x y}$ are the sample variances and covariance of the variables $x$ and $y$.

Given $\beta$ in Equation (9) and $\alpha$ in Equation (10), $x^{*}$ and $y^{*}$ can be computed by:

$$
\begin{aligned}
& x^{*}=x+\frac{\beta}{\beta^{2}+\delta}(y-\alpha-\beta x), \\
& y^{*}=\alpha+\beta x^{*} .
\end{aligned}
$$

$x^{*}$ is the CGSpread $d_{i, t}^{*}$ and $y^{*}$ is the $\operatorname{Spread}_{i, t}^{*}$.

CGSpread ${ }_{i, t}^{*}$ is the error-adjusted model spread, which is used to calculate CDS creditrelated systematic factor in Equation (6). The model spread is not likely to be completely identical with the observed spread. Their difference can be driven by the model specifi- 
cation error, and the newly arriving credit and non-credit related information impacting the current value of the CDS spread. The more important such information is relative to that already incorporated into the CG spread, the higher the observed deviation is in absolute term. The deviation $\left(C G D e v_{i, t}^{*}\right)$ between the observed and the model spreads corrected for the estimation errors is computed as follows:

$$
C G D e v_{i, t}^{*}=\mid \text { Spread }_{i, t}^{*}-\hat{\beta} C G \text { Spread }_{i, t}^{*} \mid,
$$

where $\hat{\beta}$ is the estimated TLS $\beta$ estimated from Equation (7).

This measure is similar to the uncertainty measures of Jurado, Ludvigson, and Ng (2015), which is defined as the conditional volatility (L2 norm) of a surprise component relative to the forecast of the future value of interest. In our setting, the forecasted value is represented by $\hat{\beta} C G S p r e a d_{i, t}^{*}$, and the absolute value of the deviation is the L1 norm, which is more robust to outliers than the L2 norm, a property very useful for the less liquid OTC CDS market.

We construct our second endogenous systematic CDS factors as the cross-sectional average of the natural logarithms of individual deviation measures $C G D e v_{i, t}^{*}$ :

$$
M C G D e v_{t}^{*}=\frac{1}{N_{t}} \sum_{i=1}^{N_{t}} \log C G D e v_{i, t}^{*}
$$

where $N_{t}$ is the number of available CDS observations at time $t$.

The values of $C G D e v_{i, t}^{*}$ are primarily driven by daily CDS quotes, reflecting, for example, the latest news on the firm credit quality, the expectations of the overall performance of the market or a given industry, and the current supply and demand for credit protection. This news will impact $C G D e v_{i, t}^{*}$ immediately, making it a faster-changing variable. While new information reflected in individual $C G D e v_{i, t}^{*}$ could be firm specific, $M C G D e v_{t}^{*}$ reflects changes in average market condition only, as the idiosyncratic noise is diversified away in the cross-sectional averaging process. During periods of intensive news arrival, the CDS forecasts based on the CG model become less reliable, and $M C G D e v_{t}^{*}$ captures 
the uncertainty in the CDS market, similar to the market uncertainty measure of Jurado, Ludvigson, and $\mathrm{Ng}(2015)$.

\subsection{Panel regression with systematic factors}

This section explores if the two new endogenous systematic factors help to explain changes in the individual CDS spreads. We estimate the following pooled panel regression:

$$
\Delta \log \operatorname{Spread}_{i, t}=\alpha+\beta \Delta \mathbf{X}_{\mathbf{i}, \mathbf{t}}+\gamma_{1} \Delta M C G \text { Spread }_{t}^{*}+\gamma_{2} \Delta M C G D e v_{t}^{*}+\varepsilon_{i, t}
$$

where $\Delta$ denotes a monthly difference in the corresponding variable, and $\mathbf{X}$ is the set of firm-specific control variables known to determine CDS spreads (discussed below). We calculate robust standard errors following Hoechle (2007).

If $\triangle M C G S p r e a d_{t}^{*}$ reflects the changes in the overall credit risk in the economy, then $\gamma_{1}$ will be positive and significant. If individual CDS spreads were driven by the CreditGrades model, $C G D e v_{i, t}^{*}$ would contain pure noise. In that case, $M C G D e v_{t}^{*}$ would have no information content. However, if Credit-Grades is imperfect, $C G D e v_{i, t}^{*}$ will contain firmspecific and market-wide information, and $M C G D e v_{t}^{*}$ will reflect the uncertainty of the "surprise" component of the CG model. During periods of high uncertainty, when pricing models become less reliable, the direction of the CDS spread change depends largely on the relative bargaining power and sophistication of protection buyers and sellers. Generally, banks are net buyers of CDS contracts, using them for hedging purposes, while hedge funds and insurance companies are usually the net sellers (Mengle 2007). Kolokolova, Lin, and Poon (2019) argue that the protection sellers trade more frequently than protection buyers, and there seem to be higher demand for protection than supply, leading to CDS spreads being revised faster upwards. Thus, during periods of higher uncertainty it is the protection sellers who would demand a higher premium and the CDS spreads are likely to increase, and thus we expect $\gamma_{2}$ to be positive. 
The set $\mathbf{X}$ includes credit- and liquidity-related factors. For credit risk factors, we use the following five variables, most of which capture the ability of a firm to pay its shortand long-term debt ${ }^{3}$

(i) Cash Ratio $(C R)$ determines the firm's ability to pay its debt due immediately. We expect a negative relation between firm's cash ratio and its CDS spread. Individual firms' cash ratios are calculated as:

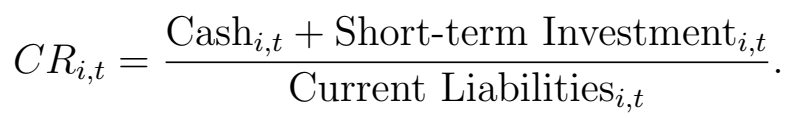

(ii) Size (Size) is another indicator for firm's default probability. Larger firms are less likely to default, as they usually have more capital, better collateral and access to additional credit, and larger loss buffers. We expect a negative relation between firm size and its CDS spread. We take the logarithm of the firm's total asset as a measure for size.

(iii) Firm Leverage (Lev) is expected to be positively related to default risk and, thus, its CDS spread. A higher leverage indicates that the firm relies more heavily on borrowing to finance its activities. In this paper, we calculate firm's accounting leverage as:

$$
\operatorname{Lev}_{i, t}=\frac{\text { Total Liabilities }_{i, t}}{\text { Total Equity }_{i, t}}
$$

We use the logarithm of $L e v_{i, t}$ in our regression.

(iv) Historical Volatility $(\mathrm{Vol})$ is expected to be positively related to a firm's CDS spread. Doshi, Ericsson, Jacobs, and Turnbull (2013), for example, show that historical volatility of the underlying stock predicts changes in CDS spreads. We estimate historical volatility using the daily stock returns over the previous one year, and use the logarithm value in our regression.

(v) Recovery Rate (Recovery) also affects CDS spreads. A higher recovery rate results in a lower CDS spread. Here, we use the reported recovery rate provided in Markit

\footnotetext{
${ }^{3}$ The accounting variables are obtained from the firm's quarterly reports. Since the model is specified at a monthly frequency, the corresponding accounting variable are held constant during each quarter, i.e., constant for every three months.
} 
database.

Several studies including Tang and Yan (2007), Das and Hanouna (2009), and Corò, Dufour, and Varotto (2013) find that CDS illiquidity risk, measured using CDS bid-ask spread, is priced in the CDS spreads. CDS bid-ask spread information, however, is not available in our sample. Goyenko, Holden, and Trzcinka (2009) show that low-frequency liquidity measures, e.g., those in Roll (1984) and Amihud (2002) based on effective spread and price impact, capture stock liquidity well, similar to high-frequency liquidly measures. In light of this evidence, we conjecture that CDS-price based liquidity measures will also capture CDS liquidity well, comparable to those constructed from CDS bid-ask spreads. We use these low frequency CDS liquidity proxies as additional controls in the regressions.

(i) Number of Contributors to CDS quotes (\#Contributor) proxies for CDS trading volume 4 . Trading volume is a useful indicator of the level of market liquidity. Higher trading volume implies more liquid markets. We therefore expect \#Contributor to be negatively related to the CDS spread.

(ii) Term Slope (CDS Slope) is the price difference between 5-year and 1-year CDSs. Term slope reflects the liquidity preference of investors.

(iii) High-minus-Low $(C D S H L)$ is the difference between highest and lowest quotes of CDS spread taken over one month. It is a proxy of a CDS bid-ask spread, and it is expected to be positively related to the spread itself.

(iv) The Roll (1984) measure (CDS Roll) is the effective bid-ask spread for an asset, computed using the serial covariance of the asset's price changes. Following Roll (1984), we calculate the individual CDS Roll measure over one month as:

$$
C D S \operatorname{Roll}_{i, t}= \begin{cases}2 \sqrt{-\operatorname{cov}\left(\Delta C D S_{t}, \Delta C D S_{t-1}\right)} & \text { if } \operatorname{cov}\left(\Delta C D S_{t}, \Delta C D S_{t-1}\right)<0 \\ 0 & \text { otherwise }\end{cases}
$$

where $\Delta$ is the operator of daily change and $C D S$ is the corresponding CDS spread.

\footnotetext{
${ }^{4}$ See Bongaerts, Jong, and Driessen (2011)
} 
(v) Days of Zero Returns ( $C D S$ Zeros) is another proxy for illiquidity, proposed in Lesmond, Ogden, and Trzcinka (1999). The more zero returns a security exhibits, the less liquid it is. We expect Zeros to be positively related to the CDS spread, and compute this measure over one month as:

$$
C D S \operatorname{Zeros}_{i, t}=\frac{\# \text { days with zero } \operatorname{return}_{i, t}}{T},
$$

where $T$ is the number of trading days in the month of interest.

(vi) The Amihud (2002) measure (CDS Amihud) is one of the most widely used measures for illiquidity. We follow Bongaerts, Jong, and Driessen (2011) and compute the CDS Amihud measure as:

$$
C D S \text { Amihud }_{i, t}=\frac{1}{N} \sum_{t=1}^{N}\left(\frac{\left|r_{t}^{C}\right|}{\# \text { Contributor }_{t}}\right)
$$

where $r^{C}$ is the daily return of the CDS spread, \#Contributor ${ }_{t}$ is the number of contributors to the CDS quotes, proxying for trading volume, and $N$ is the number of trading days in the past year.

In addition to the firm-specific factors discussed above, we include five systematic factors in previous studies as important determinants for CDS spreads. The factors include: (i) the VIX index (Diaz, Groba, and Serrano 2013, Doshi, Ericsson, Jacobs, and Turnbull 2013. Galil, Shapir, Amiram, and Ben-Zion 2014), (ii) the U.S. 5-year Treasury bond yield (Das and Hanouna 2009, Longstaff, Pan, Pedersen, and Singleton 2011), (iii) the term spread, estimated as the difference between the yields on the 10-year U.S. Treasury bonds and 3-month US Treasury bills (Galil, Shapir, Amiram, and Ben-Zion 2014 Conrad, Dittmar, and Hameed 2011 Longstaff, Pan, Pedersen, and Singleton 2011), (iv) Default Spread, computed as the difference between Moody's Baa and Aaa yields (Doshi, Ericsson, Jacobs, and Turnbull 2013, Galil, Shapir, Amiram, and Ben-Zion 2014), and (v) the overall performance of the equity market measured as the returns on the S\&P500 Index (Norden and Weber 2004, Norden and Weber 2009). Table 1 lists all the factors used in 
the regression.

[Table 1 is around here.]

\section{Data}

Our U.S. single-name CDS sample is obtained from the Markit database. The sample period is from 2002 to 2011. We focus on month-end 5-year CDSs and choose only CDSs on senior unsecured debt. We remove CDS spreads that are more than 10,000 bps, following Bai and $\mathrm{Wu}$ (2016) (cf. 16 data points are removed from the sample as a result). A CDS spread of more than 10,000 bps means that the underlying asset is likely to default within one year. We also exclude financial firms because of their peculiar capital structure. The accounting liabilities of these firms are usually much larger than their equity, resulting in mis-calculations for model spreads.

After name-matching of CDS underlying companies, their equity information from Compustat (accounting data) and CRSP (stock data), we finally have 286 matched firms with 16,097 firm-month observations in our sample. Table 2 reports the descriptive statistics for our sample CDS spreads, model spreads, and deviations before any estimation error adjustment. The sample CDS spread average is 156 bps with standard deviation of 220 bps. The average CGSpread is 161 bps, 5 bps higher than the mean of the actual CDS spreads. The standard deviation of CGSpread is 293 bps, roughly $33 \%(293 b p / 220 b p-1)$ more volatile than the actual spreads. On other hand, the deviation of the CGSpread from the actual spread (CGDev) has an average of 121 bps with standard deviation of 206 bps.

[Table 2 is around here.]

The last two panels in Table 2 report the correlation coefficients for CDS spread, model spread, and the deviation on levels in Panel B and monthly changes in Panel C. In Panel B, correlation between CGSpread and actual spread (60\%) is higher than between CGDev 
and actual spread (50\%). Monthly changes in actual spread are slightly more related to CGDev (38\%) than to CGSpread (31\%). In both panels, the highest correlation is that between CGSpread and CGDev.

Figure 1 plots the time-series of the cross-sectional averages of observed CDS spread (AvgSpread), CG-model spread (AvgCGSpread), and absolute deviations (AvgCGDev). These three variables clearly co-move. During the 2007-2009 financial crisis, the values of all three variables increase dramatically. Notably, AvgCGSpread is well above AvgSpread during 2008 and 2010, but lower during other periods. AvgCGDev is relatively stable before 2007, but becomes more volatile afterwards.

[Figure 1 is around here.]

Table 3 reports the descriptive statistics for the control variables. The accounting data are obtained from the quarterly reports of the firms. The average cash ratio is $46.3 \%$ with the standard deviation of $64.6 \%$. The accounting leverage is approximately $29 \%$ (equivalent to $\exp (-1.23)$ ), with the standard deviation of 1.82 (equivalent to $\exp (0.60)$ ). For our low-frequency illiquidity measures, the average difference between 5 -year and 1 year CDS spread (CDS Slope) is 62 bps. The average for $C D S H L$ is 28 bps and for CDS Roll is just 2 bps. Both $C D S H L$ and $C D S$ Roll are proxies for bid-ask spread, but CDS Roll is on average smaller than $C D S H L$. Since $C D S$ Roll is estimated using the daily CDS spread changes, the low estimated value suggests the absence of big spikes in daily changes in CDS.

[Table 3 is around here.] 


\section{$5 \quad$ Empirical results}

\subsection{Estimation-error adjustment}

Table 4 reports the estimation results for the regression of the observed CDS spread on the CG-model values (Equation (7)), in levels and in monthly changes. The left panel is estimated using simple OLS, whereas the right panel employs the TLS methodology and corrects for the estimation error.

The slope coefficients for CGSpread and $\triangle$ CGSpread are 0.448 and 0.290 , respectively, for the OLS estimation. Both reject the hull hypothesis $\beta=1$ at the $1 \%$ level. The R-square is lower when we use the monthly changes in spreads, implying that the monthly innovations of CDS spreads strongly depend on factors other than model spread. For the TLS regression, the slope coefficients for CGSpread and $\Delta C G S p r e a d$ increase substantially to 0.625 and 0.836 , respectively. The slope coefficients are much closer to 1 after we control for estimation errors, compared to the OLS regression results, however, the null hypothesis of $\beta=1$ is still rejected at the $1 \%$ level for both regressions. The slope coefficients are still smaller than 1 even for the TLS specification, indicating that the CGSpread, on average, overestimates the actual CDS spread. Figure 1 suggests that such overestimation may have resulted from rather higher model spreads during the 2007-2009 financial crisis. The R-squares increase from 36\% for the OLS to $64 \%$ for the TLS regressions for CDS spread levels, and from $9 \%$ to $57 \%$ for CDS spread changes. It highlights the importance of controlling for the estimation error, and further supports the findings in Bai and $\mathrm{Wu}$ (2016), where the authors emphasize the importance of fundamental credit factors in determining the actual CDS spread. However, even after controlling for the model estimation error, about $36 \%$ of the actual spread level variation and $43 \%$ of the variation in monthly changes in spreads cannot be explained by the theoretical spread.

[Table 4 is around here.]

To evaluate the time series dynamics of our error-adjusted systematic factors, we es- 
timate an $\mathrm{AR}(1)$ model for the changes in each of the factors. The $\mathrm{AR}(1)$ coefficient for $\triangle M C G$ Spread $t_{t}^{*}$ is 0.343 , significant at the $1 \%$ level, while that of $\triangle M C G D e v_{t}^{*}$ is only 0.103 and is not statistically significant. Hence, MCGSpread $d_{t}^{*}$ is more persistent compared to $M C G D e v_{t}^{*}$.

\subsection{Drivers of individual CDS deviations}

Next, before moving to our main regression results, we examine the drivers of the individual deviations of CDS spreads from their model values. We estimate a panel regression of the monthly changes in the logarithmic deviations $\left(\Delta \log C G D e v^{*}\right)$ on the same set of firm-specific factors as in Equation (7). The residuals might be autocorrelated, heteroscedastic, and cross-sectionally dependent. Hence, we calculate the robust standard errors of the coefficients' estimates, following Hoechle (2007).

Table 5 reports the estimation results. Model 1 includes only firm-specific characteristics, whereas Model 2 includes also the two endogenous CDS-market systematic factors. Model 3 further controls for other five systematic factors. The results indicate that both credit and liquidity factors contribute to the individual deviations $\Delta \log C G D e v^{*}$. These factors are, obviously, interrelated as higher credit risk usually leads to lower liquidity (see Buhler and Trapp 2010). Firms with higher stock return volatility and higher leverage exhibit larger deviations from the model spread. Similarly, more illiquid firms tend to have higher deviations. The loadings on $\triangle C D S$ Amihud are positive and significant at the $5 \%$ to $10 \%$ levels.

As for the two CDS-market systematic factors, systematic deviation $M C G D e v^{*}$ is positively related to individual deviations with the coefficient of 0.87 being significant at the $1 \%$ level, whereas systematic credit risk factor MCGSpread* is negatively related to the individual deviations, although not statistically significant. Individual deviations in CDS spread are not driven by the common drivers of equity and bond markets. Including other systematic factors (Model 3) does not change the overall conclusion, as only changes in VIX are positively related to changes in $M C G D e v^{*}$, significant only at the $10 \%$ level. 
The explanatory power of the models is very low, with the adjusted R-square being between $0.5 \%$ and $4 \%$. It indicates that while individual credit and liquidity factors, and the endogenous systematic factors help to explain the deviation, most of it remains unexplained by the known factors.

$$
\text { [Table } 5 \text { is around here.] }
$$

\subsection{CDS spread changes and the endogenous systematic factors}

Table 6 reports the correlation coefficients among the variables. We find that individual CDS spread has a rather high correlation coefficients with stock volatility (19\%) and its accounting leverage (19\%). Stock volatility, to some degree, reflects the business risk, and leverage represents debt insolvency risk. We also find that CDS spread is related to the CDS liquidity measure $C D S H L(30 \%)$.

There is a clear systematic component in the changes of CDS spreads. The individual CDS spread changes are positively correlated with several systematic factors, including the changes in the VIX index (22\%), Default Spread (24\%), and CDS-endogenous factors MCGSpread* $(28 \%)$ and MCGDev* $(14 \%)$. The changes in Treasury bond yields, the term spread, and the returns on the S\&P500 index are only mildly correlated with the changes in the CDS spreads.

[Table 6 is around here.]

However, such a univariate analysis cannot determine which of the systematic factors the original source of impact is. The reason being that all the systematic factors are relatively highly correlated with each other. For example, the correlation coefficient of the returns on the S\&P500 index and the VIX index is $-59 \%$, and the S\&P500 index and CDS-market endogenous factors of $-21 \%$ (MCGSpread $\left.{ }^{*}\right)$ and $-16 \%\left(M C G D e v^{*}\right)$. MCGSpread* is also positively correlated with changes in the VIX $(52 \%)$ and the changes in Default Spread (49\%). This is not surprising as on declining markets (expected) return 
volatility usually increases, and so does investor risk aversion, credit risk of individual companies, and the demand for credit protection. To establish which of the systematic factors are the original drivers of CDS spread changes, we use the multivariate analysis.

Table 7 reports the regression results for Equation (15). Model 1 reports the results based on firm-specific credit risk factors only. All the factors (except for cash ratio, $C R$ ) are significant at the $1 \%$ level, and the signs of the loadings are as expected: higher $V o l$ and Lev indicate higher likelihood of a firm's default, and thus, lead to higher CDS spreads, while large firms are expected to have lower risk of default than smaller firms. Model 2 is based on firm-specific liquidity risk factors only. We find positive and significant loadings on $C D S$ Slope, CDS Amihud, and CDS HL. This indicates that CDS buyers are expected to pay more for less liquid CDS contracts. In other words, in the CDS market, the seller, not the buyer, earns the liquidity premium. The explanatory power of these models is, however, relatively small, with the adjusted R-squares being $11 \%$ and $6 \%$ respectively. Model 3 includes both firm-specific credit and liquidity factors, and the adjusted R-square further increases to $15.7 \% 5$

[Table 7 is around here.]

Models 4 to 6 report the results of the regressions including new endogenous systematic factors, individually and jointly. We find strong evidence that both our systematic factors explain the individual CDS spreads. The loadings are always positive and significant at the $1 \%$ level. Moreover, the adjusted R-square increases from 11\% in Model 1 (with only firm-specific credit factors) and $6 \%$ in Model 2 (with only firm-specific liquidity factors) to around $23 \%$ in Model 6 (two endogenous systematic factors). Model 7 reports the results for the full specification of the regression. The estimated coefficients are consistent, with an exception of $C D S$ Amihud, which looses its significance. The two endogenous systematic factors are highly significant and the adjusted R-square of the model further

\footnotetext{
${ }^{5}$ For comparison, Corò, Dufour, and Varotto (2013) find a similar R-square of $17 \%$ for the monthly changes in CDS spreads of European companies, when using firm-specific credit information and highfrequency bid-ask spread as liquidity factors. This indicates that the low-frequency liquidity measures used in our regressions can capture CDS liquidity well, similar to what Goyenko, Holden, and Trzcinka (2009) concluded for the stock market.
} 
increases to $28 \%$. The results in Table 7 highlight the importance of the two endogenous systematic factors within the CDS market. Both systematic factors, capturing slowmoving credit-related information and fast-moving market uncertaity information, play equally important roles in determining the individual CDS spreads. ${ }_{6}^{6}$

Model 8 of Table 7includes other non-CDS based competing systematic factors, viz. the VIX index, the US 5-year Treasury bond yield, the term spread, the default spread, and the S\&P500 return. The estimation result for Model 8 shows that the changes in the default spread have a positive and significant while impact on changes of individual CDS spreads while the S\&P500 returns exert a negative impact that is significant at the $10 \%$ level. Other non-CDS based systematic factors are not statistically significant. The endogenous CDS-market systematic factors remain highly statistically significant in the presence of the other systematic factors. Notably, the model explanatory power increases only marginally from the adjusted R-square of $28 \%$ to $30 \%$, after inclusion of other nonCDS based systematic factors. This further confirms the importance and relevance of our proposed systematic factors for CDS pricing.

Further in Model 9 we include year fixed effect to control for any possible unobserved factors, such as business cycle, which could drive the dynamics of individual CDS spreads, our endogenous systematic factors, as well as other non-CDS based systematic factors. The results show the findings reported above are robust to year fixed effects as the estimated coefficients changed only marginally.

As a robustness check, we group our individual CDSs into three general sectors: (i) a "Basic" sector, which includes firms from basic material, energy, and utility sectors; (ii) a "Consumer" sector, which includes firms from consumer goods, consumer services, and healthcare; and (iii) an "Industrial" sector, which includes firms from the technology, telecommunication, and industrial sectors. We re-run the panel regressions from Equation (15) and find qualitatively similar results for all sectors. Thus, our findings are not driven

\footnotetext{
${ }^{6}$ In unreported results, we also used a version of the systematic factors that are not adjusted for the estimation error. Both of them remain highly significant, but the explanatory power of the model is slightly lower, with an adjusted R-square $24 \%$.
} 
by any particular sector 7

\section{Out-of-sample prediction}

The analysis in the previous section implies that the two endogenous systematic factors provide cross-sectional predictability. In this section, we test the time-series predictability of the systematic factors. For all individual firms, we first perform a time-series regression on a training sub-sample, including only CDS systematic factors:

$$
\Delta \log \operatorname{Spread}_{i, t}=\alpha_{i}+\gamma_{i 1} \Delta M C G \text { Spread }_{t-1}^{*}+\gamma_{i 2} \Delta M C G D e v_{t-1}^{*}+\varepsilon_{i, t}
$$

The one-month-ahead prediction for the changes in the individual CDS spread is given by:

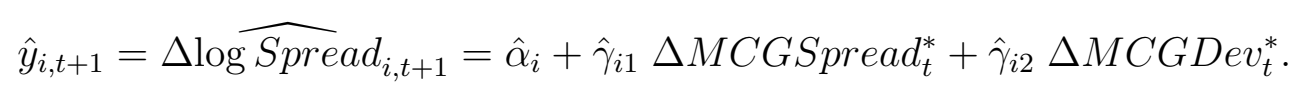

The out-of-sample performance is evaluated using the out-of-sample R-square $\left(R_{O O S}^{2}\right)$ following Welch and Goyal (2008):

$$
R_{O O S}^{2}=1-\frac{\sum_{i} \sum_{t}\left(y_{i, t+1}-\hat{y}_{i, t+1}\right)^{2} / D F_{A}}{\sum_{i} \sum_{t}\left(y_{i, t+1}-\bar{y}_{i, t+1}\right)^{2} / D F_{N}},
$$

where $y_{i, t+1}$ is the actual change in $\log C D S$ spreads in month $t+1, \bar{y}_{i, t+1}$ is our benchmark predicted value, and $D F$ is the degree of freedom for the corresponding hypothesis. The null hypothesis is that our proposed model $(\hat{y})$ does not perform better than the benchmark $(\bar{y})$. Therefore, a positive $R_{O O S}^{2}$ would indicate that the model prediction has less prediction error than the benchmark prediction, rejecting our null hypothesis.

\footnotetext{
${ }^{7}$ The results are not reported here to save space, but are available upon request.
} 
We select three different training periods: 1 year, 2 years, and 3 years, to assess the stability of the predictions over longer training period. For out-of-sample benchmark $(\bar{y})$, we consider four benchmarks: (1) "Hist Avg", using the average changes in logarithm of CDS spreads over the training period (i.e. $\bar{y}_{i, t+1}={\overline{\Delta \log \text { Spread }_{i, t}}}_{=}$ $\sum_{t=t-n+1}^{t} \Delta \log$ Spread $_{i, t} / n, \mathrm{t}=12,24$, or 36 months); (2) "Past 1Mth", using the latest changes in logarithm of CDS spread (i.e. $\bar{y}_{i, t+1}=\Delta \log$ Spread $_{i, t}$ ); (3) "CG-Spread", using the latest changes in logarithm of CG-model spread (i.e. $\bar{y}_{i, t+1}=\Delta \log C G$ Spread $_{i, t}$ ), and (4) "Past 12Mth", using the average changes in logarithm of CDS spreads over the previous 12 months, which coincides with the historical average for the one-year estimation, but provides a more "immediate" benchmark when longer estimation periods are used.

Table 8 reports the out-of-sample performance of the CDS systematic factors. Panels $\mathrm{A}, \mathrm{B}$, and $\mathrm{C}$ report the results for different training periods. We also report the results using different factors and sectors. For factor analysis, "MCGSpread* + MCGDev" is the original specification, that includes both factors, while "MCGSpread* only" (or "MCGDev* only") uses only $\triangle M C G S p r e a d^{*}$ (or $\triangle M C G D e v^{*}$ ) to estimate the coefficients in Equation (16). By doing so, we evaluate the predictive power of each of the systematic factors individually. We also report the out-of-sample performance separately for the three general economic sectors, using the two endogenous systematic factors.

[Table 8 is around here.]

The results depict a consistent picture of a positive OOS R-square for all training periods, benchmarks, and sectors. Hence the proposed CDS-specific systematic factors indeed improve time-series predictions for changes in individual spreads. The best results are achieved for a one-year training period when both MCGSpread* and MCGDev* factors are used together. At the same time, even taken individually, these factors always improve predictions relative to the benchmarks and exhibit a positive R-square.

Another notable finding is that $\triangle M C G S p r e a d^{*}$ has slightly better predictive power than $\triangle M C G D e v^{*}$, although the individual OOS R-squares are very close. This indicates that both the credit-related systematic information the CDS market uncertainty measure 
not captured by $\triangle M C G S p r e a d^{*}$ play equally important role in predicting changes in CDS spreads.

\section{$7 \quad$ Extensions and robustness}

In this section we, first, evaluate the robustness of our results to higher frequency of CDS spread changes, and then consider a different specification of the CDS deviation factor, which is adjusted for the effect of various CDS specific and systematic factors.

\subsection{Weekly changes of CDS spreads}

In the main body of the paper we focus on monthly changes in CDS spreads. In this section we further check if the effect of CDS-market systematic factors is also pronounced for weekly changed in CDS spreads. For example, analyzing the lag-lead relations between CDS, stock, and bond markets, Norden and Weber (2009) found that the direction of the relations in consistent for monthly, weekly, and daily changes, although the explanatory power of the model based on monthly changes is higher than that based on weekly or daily changes. Table 9 reports the panel regression results as specified in Equation (15), where all changes are weekly. Similar to Norden and Weber (2009), using weekly changes instead of monthly does not qualitatively affect the results, but the model explanatory power decreases. The relations between endogenous CDS-market systematic factors and the changes in the individual CDS spreads remain positive and highly significant, but the adjusted R-square drops from $30 \%$ for monthly changes to $16 \%$ for weekly changes in CDS spreads.

[Table 9 is around here.] 


\subsection{Factor adjusted deviation specification}

The individual firm deviation measures $C G D e v_{i, t}^{*}$ can be partly explained by firm-specific credit and liquidity factors as reported in Table 5. The factors, however, explain less than $4 \%$ of the variation of the changes in the deviation. In this section, as a robustness check, we consider a different specification for the individual deviation, namely, factor adjusted deviations. We start by re-estimating (controlling for estimation errors) Equation (7) including all the control variables used in Equation (15) $\mathbf{X}_{\mathbf{i}, \mathbf{t}}$ :

$$
\text { Spread }_{i, t}=\alpha+\beta \text { CGSpread } i, t+\gamma \mathbf{X}_{\mathbf{i}, \mathbf{t}}+\varepsilon_{i, t} .
$$

We then compute the individual factor adjusted deviation measure as the absolute difference between the observed error-adjusted spread and its fitted error-adjusted value:

$$
\widetilde{C \operatorname{Gev}_{i, t}^{*}}=\mid \operatorname{Spread}_{i, t}^{*}-\left(\hat{\beta} C G \text { Spread }_{i, t}^{*}+\hat{\gamma} \mathbf{X}_{\mathbf{i}, \mathbf{t}}^{*}\right) \mid
$$

and proceed with computing the systematic deviation measure as the cross-sectional average of the logarithmic $C \widetilde{G D e v_{i, t}^{*}}$ as previously.

Table 10 reports the panel regression results as specified in Equation (15), where the new $M \widetilde{C G D e v} v_{t}^{*}$ measure is used.

[Table 10 is around here.]

Overall, the results are robust to the orthogonalization of our CDS deviation factor with respect to other drivers of CDS spreads, and remain qualitatively unchanged compared to the ones reported in Table 7. Taken alone, $M \widetilde{C G D} v_{t}^{*}$ becomes even a stronger driver of CDS spreads, explaining $19 \%$ of variation in changes in individual CDS spread, up from the adjusted R-square of $14 \%$ reported in Table 7. 


\subsection{Wavelet analysis of the CDS systematic factors}

As a robustness check, in this sub-section, we employ wavelet analysis to check if there is any time series pattern in the two systematic factors. We follow Huang, Shen, Long, Wu, Shih, Zheng, Yen, Tung, and Liu (1998) to identify orthogonal wavelets - Intrinsic Mode Functions $(I M F)$ - for $\triangle M C G S p r e a d^{*}$ and $\triangle M C G D e v^{*}$. Every time series $y_{t}$ can be decomposed into a sum of $\mathrm{N}$ orthogonal wavelets and a residual term:

$$
y_{t}=\sum_{i=1}^{N} I M F_{i, t}+\text { Residual }_{t} .
$$

Using this decomposition, we identified five wavelets for $\Delta M C G S p r e a d^{*}$, and four wavelets for $\triangle M C G D e v^{*}$. The cross-correlation between these two sets of IMFs is reported in Table 11, indicating some level of dependence between the IMFs, consistent with the results reported in Table 6. The identified wavelets themselves, however, do not seem to have any clear structure.

[Table 11 is around here.]

\section{Conclusion}

In this paper, we study the 5-year CDS spreads for a sample of U.S. non-financial firms from 2002 to 2011. We construct new endogenous CDS-market systematic factors based on a widely used in the industry CreditGrades (CG) model, and find that the impact of these endogenous systematic factors on CDS spreads is stronger than that of firm-specific variables.

The proposed systematic factors capture two types of information contained in the CDS spreads: slow-moving credit-risk information and newly arrived market information which might be unrelated to credit quality and also picks up the CDS market uncertainty. 
We capture the credit-related information though the CreditGrades model, and the newly arrived information though the absolute deviations of the observed spread from the modeled ones. We use the total least squares regression to control for model estimation error, and adjust the model spreads and the deviations for the estimation error. Such an adjustment reduces the noise and increases the information content of the two factors, which are constructed as the cross-sectional averages of the error-adjusted individual firms' model spreads and deviations.

These two new factors, capturing peer information in the CDS market, are important predictors of the changes in the CDS spread and dominate firm-specific variables. The individual firms' credit-risk related variables can capture only up to $11 \%$ of the variation of changes in CDS spreads, whereas our endogenous systematic factors alone capture about $23 \%$ of the variation. We show that our endogenous systematic factors also dominate other commonly known systematic factors. The VIX index, the U.S. 5-year Treasury bond yield, and the term spread, estimated as the difference between the yields on the 10-year US Treasury bonds and 3-month U.S. Treasury bills, are all not significant in the presence of the two new endogenous factors. The endogenous factors provide good out-of-sample predictions, and are most powerful with a one-year estimation window.

Financial regulations, such as Basel III, stipulate that CDS spreads must be used to produce market estimates of the default probability of a counterparty. Our findings caution this approach as changes of individual firms' CDS spreads are driven mainly by systematic factors, rather than by pure individual firm's default risk. Moreover, since they are systematic, it suggests that using CDSs in risk management will be pro-cyclical, creating more instabilities during crisis. 


\section{References}

Acharya, V. and T. Johnson (2007). Insider trading in credit derivatives. Journal of Financial Economics 84(1), 110-141.

Almeida, H. and T. Philippon (2007). The risk-adjusted cost of financial distress. The Journal of Finance 62(6), 2557-2586.

Amihud, Y. (2002). Illiquidity and stock returns: Cross-section and time-series effects. Journal of Financial Markets 5, 31-56.

Arora, N., P. Gandhi, and F. A. Longstaff (2012). Counterparty credit risk and the credit default swap market. Journal of Financial Economics 103(2), 280 - 293.

Bai, J. and L. Wu (2016). Anchoring credit default swap spreads to firm fundamentals. Journal of Financial and Quantitative Analysis 51(5), 1521-1543.

Bao, J. and J. Pan (2013). Bond illiquidity and excess volatility. Review of Financial Studies 26(12), 3068-3103.

Basel Committee (2010). Basel III: A global regulatory framework for more resilient banks and banking systems. Basel Committee on Banking Supervision, Basel.

Bedendo, M., L. Cathcart, and L. El-Jahel (2011). Market and model credit default swap spreads: Mind the gap! European Financial Management 17, 655-678.

Blanco, R., S. Brennan, and I. W. Marsh (2005). An empirical analysis of the dynamic relationship between investment-grade bonds and credit default swaps. Journal of Finance 60(5), 3-32.

Bongaerts, D., F. Jong, and J. Driessen (2011). Derivative pricing with liquidity risk: Theory and evidence from the credit default swap market. Journal of Finance 66, 203-240.

Buhler, W. and M. Trapp (2010). Time-varying credit risk and liquidity premia in bond and CDS markets. Working Paper.

Cespa, G. and T. Foucault (2014). Illiquidity contagion and liquidity crashes. Review of Financial Studies 27, 1615-1660.

Chen, F., X. Chen, Z. Sun, T. Yu, and M. Zhong (2013). Systemic risk, financial crisis, and credit risk insurance. The Financial Review 48(3), 417-442. 
Choi, J. and M. Richardson (2016). The volatility of a firm's assets and the leverage effect. Journal of Financial Economics 121(2), 254-277.

Chou, R. Y. (1988). Volatility persistence and stock valuations: Some empirical evidence using garch. Journal of Applied Econometrics 3(4), 279-294.

Collin-Dufresn, P., R. S. Goldstein, and J. S. Martin (2001). The determinants of credit spread changes. The Journal of Finance 56(6), 2177-2207.

Conrad, J., R. Dittmar, and A. Hameed (2011). Cross-market and cross-firm effects in implied default probabilities and recovery values. Working Paper.

Corò, F., A. Dufour, and S. Varotto (2013). Credit and liquidity components of corporate CDS spreads. Journal of Banking \&6 Finance 37, 5511-5525.

Das, S. R. and P. Hanouna (2009). Hedging credit: Equity liquidity matters. Journal of Financial Intermediation 18, 112-123.

Deming, W. E. (1943). Statistical Adjustment of Data. Wiley.

Diaz, A., J. Groba, and P. Serrano (2013). What drives corporate default risk premia? evidence from the cds market. Journal of International Money and Finance 37, $529-563$.

Doshi, H., J. Ericsson, K. Jacobs, and S. M. Turnbull (2013). Pricing credit default swaps with observable covariates. Review of Financial Studies 26(8), 2049-2094.

Eom, Y. H., J. Helwege, and J.-Z. Huang (2004). Structural models of corporate bond pricing: An empirical analysis. Review of Financial Studies 17(2), 499-544.

Ericsson, J., K. Jacobs, and R. Oviedo (2009). The determinants of credit default swap premia. Journal of Financial and Quantitative Analysis 44(1), 109-132.

Ericsson, J., J. Reneby, and H. Wang (2015). Can structural models price default risk? Evidence from bond and credit derivative markets. Quarterly Journal of Finance 5(3), 1550007.

Fan, H. and S. Sundaresan (2000). Debt valuation, renegotiation, and optimal dividend policy. Review of Financial Studies 13(4), 1057-1099.

Finger, C., V. Finkelstein, J.-P. Lardy, G. Pan, T. Ta, and J. Tierney (2002). CreditGrades technical document. Technical report, RiskMetrics Group. 
Galil, K., O. M. Shapir, D. Amiram, and U. Ben-Zion (2014). The determinants of CDS spreads. Journal of Banking \& Finance 41, 271-282.

Gennotte, G. and H. Leland (1990). Market liquidity, hedging, and crashes. American Economic Review 80, 999-1021.

Goyenko, R., C. Holden, and C. Trzcinka (2009). Do liquidity measures measure liquidity? Journal of Financial Economics 92, 153-181.

Hammoudeh, S., R. Bhar, and T. Liu (2013). Relationships between financial sectors' CDS spreads and other gauges of risk: Did the great recession change them? The Financial Review 48(1), 151-178.

Hanousek, J. and A. Shamshur (2011). A stubborn persistence: Is the stability of leverage ratios determined by the stability of the economy? Journal of Corporate Finance 17(5), 1360-1376.

Hoechle, D. (2007). Robust standard errors for panel regressions with cross-sectional dependence. Stata Journal 7(3), 281.

Huang, H. H., H.-Y. Huang, and J. Oxman (2015). Stock market liquidity and corporate bond yield spreads: Theory and evidence. Journal of Financial Research 38(1), 5991.

Huang, N. E., Z. Shen, S. R. Long, M. C. Wu, H. H. Shih, Q. Zheng, N.-C. Yen, C. C. Tung, and H. H. Liu (1998). The empirical mode decomposition and the hilbert spectrum for nonlinear and non-stationary time series analysis. Proceedings of the Royal Society of London. Series A: Mathematical, Physical and Engineering Sciences 454(1971), 903-995.

Jorion, P. and G. Zhang (2009). Credit contagion from counterparty risk. The Journal of Finance 64(5), 2053-2087.

Jurado, K., S. C. Ludvigson, and S. Ng (2015, March). Measuring uncertainty. American Economic Review 105(3), 1177-1216.

Kolokolova, O., M.-T. Lin, and S.-H. Poon (2019, May). Rating-based CDS curves. The European Journal of Finance 25(7), 689-723.

Leland, H. E. and K. B. Toft (1996). Optimal capital structure, endogenous bankruptcy, 
and the term structure of credit spreads. Journal of Finance 51, 987-1019.

Lemmon, M. L., M. R. Roberts, and J. F. Zender (2008). Back to the beginning: Persistence and the cross-section of corporate capital structure. The Journal of Finance 63(4), 1575-1608.

Lesmond, D. A., J. P. Ogden, and C. A. Trzcinka (1999). A new estimate of transaction costs. Review of Financial Studies 12, 1113-1141.

Longstaff, F. A., J. Pan, L. H. Pedersen, and K. J. Singleton (2011). How sovereign is sovereign credit risk? American Economic Journal: Macroeconomics 3(2), 75-103.

Mayordomo, S., J. I. Peña, and E. S. Schwartz (2014). Are all credit default swap databases equal? European Financial Management 20, 677-713.

Mengle, D. (2007). Are all credit default swap databases equal? Economic Review Federal Reserve Bank of Atlanta 92(4), 1-24.

Merton, R. C. (1974). On the pricing of corporate debt: The risk structure of interest rates. Journal of Finance 29, 449-470.

Norden, L. and M. Weber (2004). Informational efficiency of credit default swap and stock markets: The impact of credit rating announcements. Journal of Banking and Finance 28(11), 2813-2843.

Norden, L. and M. Weber (2009). The comovement of credit default swap, bond and stock markets: An empirical analysis. European Financial Management 15(3), 529562.

Roll, R. (1984). A simple implicit measure of the effective bid-ask spread in an efficient market. Journal of Finance 39(4), 1127-1139.

Stamicar, R. and C. Finger (2006). Incorporating equity derivatives into the creditgrades model. Journal of Credit Risk 2(1), 1-20.

Tang, D. and H. Yan (2007). Liquidity and credit default swap spreads. Working Paper.

Welch, I. and A. Goyal (2008). A comprehensive look at the empirical performance of equity premium prediction. Review of Financial Studies 21, 1455-1508.

Yu, F. (2006). How profitable is capital structure arbitrage? Financial Analysts Journal 62(5), 47-62. 
Zhang, B. Y., H. Zhou, and H. Zhu (2009). Explaining credit default swap spreads with the equity volatility and jump risks of individual firms. The Review of Financial Studies 22(12), 5099-5131. 
Table 1: Descriptive statistics of CDS spreads and their unadjusted components

This table lists firm-specific and systematic factors used in the regressions together with their brief definitions.

\begin{tabular}{ll}
\hline Factor & Definition \\
\hline log Spread & The logarithm of the observed 5-year CDS spread. \\
CR & The firm's cash ratio. \\
Size & The logarithm of firm's accounting total assets. \\
Vol & The logarithm of the stock return volatility over one previous year. \\
Lev & The logarithm of firm's accounting leverage ratio. \\
Recovery & The reported CDS recovery rate provided by Markit. \\
\#Contributor & the number of contributors to CDS quotes in Markit. \\
CDS Slope & the difference between 5-year CDS and 1-year CDS spreads. \\
CDS Amihud & The Amihud (2002) measure of the CDS spreads over one year. \\
CDS HL & The high-minus-low of the 5-year CDS over one month. \\
CDS Roll & The Roll (1984) measure of the CDS spread over one month. \\
CDS Zeros & The proportion of zero CDS returns over one month. \\
VIX & The value of the VIX index. \\
Treasury & The US 5-year Treasury bond yield. \\
TermSpread & The difference between the yields on the 10-year US Treasury bonds and 3-month US Treasury bills. \\
DefaultSpread & The difference between Moody's Baa and Aaa yields. \\
S\&P500 & The value of the S\&P500 Index. \\
MCGSpread* & The first endogenous CDS systematic factor, based on the error adjusted average credit-grade spread. \\
MCGDev* & The second endogenous CDS systematic factor, based on the error adjusted residuals. \\
\hline
\end{tabular}


Table 2: Descriptive statistics of CDS spreads and their unadjusted components

This table reports the descriptive statistics and the correlation coefficients for the actual 5year CDS spreads (Spread), the CreditGrades model implied CDS spread (CGSpread) and the difference between the actual and implied CDS spreads (CGDev). The sample period is from 2002 to 2011. Panel A reports the sample means, standard deviations, maximums, and minimums. Panel B reports the correlation coefficients of the variables. Panel $\mathrm{C}$ reports the correlation coefficients for the monthly changes $(\Delta)$ in the variables. The number of the observations for each variable is 16,097.

Panel A: Descriptive Statistics

\begin{tabular}{lrrr}
\hline & Spread & CGSpread & CGDev \\
\hline Mean & 0.0156 & 0.0161 & 0.0121 \\
Std & 0.0220 & 0.0293 & 0.0206 \\
Max & 0.7108 & 0.5566 & 0.5188 \\
Min & 0.0003 & 0.0000 & 0.0000 \\
\hline
\end{tabular}

Panel B: Correlation (Level)

\begin{tabular}{lrr}
\hline & CGSpread & CGDev \\
\hline Spread & 0.60 & 0.50 \\
CGSpread & & 0.81 \\
CGDev & & \\
\hline
\end{tabular}

Panel C: Correlation (Change)

\begin{tabular}{lrr}
\hline & $\Delta$ CGSpread & $\Delta$ CGDev \\
\hline$\Delta$ Spread & 0.31 & 0.38 \\
$\Delta$ CGSpread & & 0.61 \\
$\Delta$ CGDev & & \\
\hline
\end{tabular}


Table 3: Descriptive statistics of the control variables

This table reports the descriptive statistics for firm-specific control variables, including sample mean, standard deviation, maximum, and minimum. The sample period is from 2002 to 2011. The variable are defined in Table 1 The number of the observations for each variable is 16,097 .

\begin{tabular}{lrrrr}
\hline & Mean & Std & Max & Min \\
\hline CR & 0.463 & 0.646 & 8.782 & 0.000 \\
Size & 8.953 & 1.263 & 12.710 & 1.740 \\
Vol & -1.118 & 0.449 & 0.859 & -3.067 \\
Lev & -1.230 & 0.602 & -0.083 & -5.133 \\
Recovery & 0.395 & 0.023 & 0.750 & 0.100 \\
\hline \#Contributor & 6.061 & 3.264 & 25.000 & 2.000 \\
CDS Zeros & 0.150 & 0.251 & 1.000 & 0.000 \\
CDS Amihud & 0.004 & 0.003 & 0.065 & 0.000 \\
CDS Slope $(\times 10,000)$ & 62 & 84 & 1208 & -1884 \\
CDS HL $(\times 10,000)$ & 28 & 82 & 2982 & 0 \\
CDS Roll $(\times 10,000)$ & 2 & 15 & 884 & 0 \\
\hline
\end{tabular}


Table 4: CDS Spread and the CG-model Spread: OLS vs. TLS

This table reports the results for regressing actual spread on CG-model spread, using linear OLS or TLS (total least squares) regressions. The sample period is from 2002 to 2011. Spread is the observed 5-year CDS spread and CGSpread is the CG-model CDS spread. $\Delta$ is the monthly change operator. The standard error of the coefficients are reported in ( ). ***, **, ${ }^{*}$ stand for the statistical significance at the $1 \%, 5 \%$, and $10 \%$ levels, respectively.

\begin{tabular}{|c|c|c|c|c|c|c|}
\hline & \multicolumn{3}{|c|}{ Ordinary Least Squares } & \multicolumn{3}{|c|}{ Total Least Squares } \\
\hline & Intercept & Slope & $\mathrm{R}$-sqr & Intercept & Slope & $\mathrm{R}$-sqr \\
\hline Spread $=\alpha+\beta \times C G$ Spread & $\begin{array}{r}0.008^{* * *} \\
(0.000)\end{array}$ & $\begin{array}{r}0.448^{* * *} \\
(0.005)\end{array}$ & 0.356 & $\begin{array}{r}0.005^{* * *} \\
(0.000)\end{array}$ & $\begin{array}{r}0.625^{* * *} \\
(0.004)\end{array}$ & 0.638 \\
\hline $\begin{array}{l}\Delta \text { Spread }= \\
\alpha+\beta \times \Delta C G \text { Spread }\end{array}$ & $\begin{array}{r}0.000 \\
(0.000)\end{array}$ & $\begin{array}{r}0.290^{* * *} \\
(0.007)\end{array}$ & 0.094 & $\begin{array}{r}0.000 \\
(0.000)\end{array}$ & $\begin{array}{r}0.836^{* * *} \\
(0.005)\end{array}$ & 0.571 \\
\hline
\end{tabular}


Table 5: Panel Regression for Deviations of Individual CDS Spreads from Their Model Values

This table reports the panel regression results for absolute deviations of individual CDS spreads from their CG-model values after controlling for the estimation error $\left(C G D e v^{*}\right)$. The sample period is from 2002 to 2011. MCGSpread ${ }^{*}$ and MCGDev* are the endogenous CDS-market systematic factors. $\Delta$ is the monthly change operator. The control variables are defined in Table 1. The standard errors of the coefficients re reported in ( ), where the robust variance-covariance is used following Hoechle (2007). ***, **, * stand for the statistical significance at the $1 \%, 5 \%$, and $10 \%$ levels, respectively.

\begin{tabular}{|c|c|c|c|}
\hline & \multicolumn{3}{|c|}{$\Delta \log$ CGDev $^{*}$} \\
\hline & Model 1 & Model 2 & Model 3 \\
\hline \multirow[t]{2}{*}{ Constant } & 0.002 & -0.000 & -0.000 \\
\hline & $(0.005)$ & $(0.001)$ & $(0.001)$ \\
\hline \multirow[t]{2}{*}{$\Delta \mathrm{CR}$} & 0.001 & 0.002 & 0.003 \\
\hline & $(0.005)$ & $(0.005)$ & $(0.005)$ \\
\hline \multirow[t]{2}{*}{$\Delta$ Size } & -0.043 & -0.041 & -0.039 \\
\hline & $(0.029)$ & $(0.025)$ & $(0.025)$ \\
\hline \multirow[t]{2}{*}{$\Delta \mathrm{Vol}$} & $0.103^{* * *}$ & 0.044 & 0.047 \\
\hline & $(0.031)$ & $(0.029)$ & $(0.030)$ \\
\hline \multirow{2}{*}{$\Delta$ Lev } & $0.099^{* * *}$ & $0.061 * * *$ & $0.058 * * *$ \\
\hline & $(0.023)$ & $(0.017)$ & $(0.017)$ \\
\hline \multirow[t]{2}{*}{$\Delta$ Recovery } & 0.144 & $0.254^{*}$ & $0.258^{*}$ \\
\hline & $(0.149)$ & $(0.133)$ & $(0.133)$ \\
\hline \multirow[t]{2}{*}{$\Delta \#$ Contributor } & 0.001 & 0.001 & 0.001 \\
\hline & $(0.001)$ & $(0.001)$ & $(0.001)$ \\
\hline \multirow[t]{2}{*}{$\Delta \mathrm{CDS}$ Slope } & $1.159^{* * *}$ & $0.611^{* *}$ & $0.592^{* *}$ \\
\hline & $(0.361)$ & $(0.273)$ & $(0.276)$ \\
\hline \multirow[t]{2}{*}{$\Delta \mathrm{CDS}$ Amihud } & $5.966^{*}$ & $6.273^{* *}$ & $6.424^{* *}$ \\
\hline & $(3.430)$ & $(2.877)$ & $(2.885)$ \\
\hline \multirow[t]{2}{*}{$\Delta \mathrm{CDS} H \mathrm{HL}$} & 0.171 & -0.083 & -0.126 \\
\hline & $(0.174)$ & $(0.196)$ & $(0.194)$ \\
\hline \multirow[t]{2}{*}{$\Delta$ CDS Roll } & 0.178 & -0.032 & 0.012 \\
\hline & $(0.476)$ & $(0.349)$ & $(0.344)$ \\
\hline \multirow[t]{2}{*}{$\Delta$ CDS Zeros } & 0.023 & 0.025 & 0.026 \\
\hline & $(0.016)$ & $(0.016)$ & $(0.016)$ \\
\hline \multirow[t]{2}{*}{$\Delta M C G$ Spread ${ }^{*}$} & & -0.028 & $-0.038^{*}$ \\
\hline & & $(0.020)$ & $(0.022)$ \\
\hline \multirow[t]{2}{*}{$\triangle M C G D e v^{*}$} & & $0.869 * * *$ & $0.874^{* * *}$ \\
\hline & & $(0.060)$ & $(0.062)$ \\
\hline \multirow{2}{*}{$\Delta \mathrm{VIX}$} & & & $0.001^{*}$ \\
\hline & & & $(0.000)$ \\
\hline \multirow[t]{2}{*}{$\Delta$ Treasury } & & & -0.604 \\
\hline & & & $(0.667)$ \\
\hline \multirow[t]{2}{*}{$\Delta$ TermSpread } & & & -0.427 \\
\hline & & & $(0.832)$ \\
\hline \multirow[t]{2}{*}{$\Delta$ DefaultSpread } & & & -0.176 \\
\hline & & & $(0.924)$ \\
\hline \multirow[t]{2}{*}{$\Delta \mathrm{S} \& \mathrm{P} 500$} & & & 0.030 \\
\hline & & & $(0.030)$ \\
\hline Adj. R-sqr & 0.005 & 0.040 & 0.039 \\
\hline $\mathrm{N}$ & 15811 & 15811 & 15811 \\
\hline
\end{tabular}


Table 6: Factor Correlation

This table reports factor correlation coefficients. The sample period is from 2002 to 2011. log Spread is the logarithm of the observed 5-year CDS spread. MCGSpread ${ }^{*}$ and $M C G D e v^{*}$ are the endogenous CDS-market systematic factors. $\Delta$ is the monthly change operator. Other variables are defined in Table 1 .

\begin{tabular}{|c|c|c|c|c|c|c|c|c|c|c|c|c|c|c|c|c|c|c|c|}
\hline & & {$[2]$} & {$[3]$} & [4] & {$[5]$} & {$[6]$} & {$[7]$} & {$[8]$} & {$[9]$} & {$[10]$} & {$[11]$} & {$[12]$} & [13] & {$[14]$} & {$[15]$} & {$[16]$} & {$[17]$} & {$[18]$} & {$[19]$} \\
\hline$\Delta \log$ Spread & {$[1]$} & -0.020 & 0.010 & 0.186 & 0.189 & -0.090 & -0.006 & -0.240 & 0.074 & 0.301 & 0.110 & 0.006 & 0.224 & -0.120 & 0.019 & 0.244 & -0.090 & 0.280 & 0.141 \\
\hline$\Delta \mathrm{CR}$ & {$[2]$} & & 0.010 & -0.009 & -0.032 & -0.025 & 0.009 & 0.011 & -0.031 & -0.019 & -0.001 & -0.010 & -0.022 & 0.016 & 0.001 & -0.022 & 0.000 & -0.031 & -0.012 \\
\hline$\Delta$ Size & [3] & & & -0.050 & 0.334 & 0.020 & 0.009 & -0.014 & -0.003 & 0.021 & -0.009 & -0.008 & 0.018 & 0.024 & 0.005 & -0.001 & -0.012 & -0.012 & 0.017 \\
\hline$\Delta \mathrm{Vol}$ & {$[4]$} & & & & 0.210 & -0.025 & -0.015 & -0.038 & 0.150 & 0.111 & 0.030 & 0.022 & 0.220 & -0.244 & 0.126 & 0.398 & 0.020 & 0.571 & 0.185 \\
\hline$\Delta \mathrm{Lev}$ & {$[5]$} & & & & & -0.021 & -0.004 & -0.008 & 0.049 & 0.069 & 0.015 & 0.003 & 0.315 & -0.161 & 0.043 & 0.222 & -0.192 & 0.321 & 0.140 \\
\hline$\Delta$ Recovery & {$[6]$} & & & & & & 0.009 & 0.052 & 0.015 & -0.032 & 0.023 & 0.008 & -0.018 & 0.039 & 0.003 & -0.029 & -0.003 & -0.040 & -0.035 \\
\hline$\Delta \#$ Contributor & {$[7]$} & & & & & & & 0.003 & -0.017 & 0.019 & -0.007 & -0.080 & -0.027 & 0.030 & -0.022 & -0.017 & 0.006 & 0.001 & -0.009 \\
\hline$\Delta$ CDS Slope & [8] & & & & & & & & -0.038 & -0.258 & -0.327 & -0.012 & 0.005 & 0.001 & -0.016 & -0.063 & -0.024 & -0.017 & 0.035 \\
\hline$\Delta \mathrm{CDS}$ Amihud & {$[9]$} & & & & & & & & & 0.183 & 0.131 & -0.035 & 0.046 & -0.063 & 0.069 & 0.094 & -0.008 & 0.132 & 0.033 \\
\hline$\Delta \mathrm{CDS} H L$ & [10] & & & & & & & & & & 0.443 & -0.039 & 0.136 & -0.036 & 0.021 & 0.163 & -0.015 & 0.131 & 0.055 \\
\hline$\Delta$ CDS Roll & {$[11]$} & & & & & & & & & & & -0.013 & 0.013 & -0.011 & -0.006 & 0.044 & -0.007 & 0.029 & 0.012 \\
\hline$\Delta$ CDS Zeros & {$[12]$} & & & & & & & & & & & & 0.009 & -0.018 & 0.022 & 0.040 & -0.011 & 0.027 & -0.003 \\
\hline$\Delta \mathrm{VIX}$ & {$[13]$} & & & & & & & & & & & & & -0.170 & 0.040 & 0.343 & -0.594 & 0.523 & 0.271 \\
\hline$\Delta$ Treasury & {$[14]$} & & & & & & & & & & & & & & 0.305 & -0.393 & -0.035 & -0.360 & -0.224 \\
\hline$\Delta$ TermSpread & {$[15]$} & & & & & & & & & & & & & & & -0.007 & 0.023 & 0.106 & 0.105 \\
\hline$\Delta$ DefaultSpread & {$[16]$} & & & & & & & & & & & & & & & & 0.128 & 0.492 & 0.181 \\
\hline$\Delta \mathrm{S} \& \mathrm{P} 500$ & {$[17]$} & & & & & & & & & & & & & & & & & -0.207 & -0.156 \\
\hline$\Delta$ MCGSpread* & {$[18]$} & & & & & & & & & & & & & & & & & & 0.568 \\
\hline$\Delta \mathrm{MCGDev}^{*}$ & {$[19]$} & & & & & & & & & & & & & & & & & & \\
\hline
\end{tabular}




\section{Table 7: CDS Systematic Factor Panel Regression}

This table reports the panel regression results for CDS systematic factors. The sample period is from 2002 to 2011. log Spread is the logarithm of the observed 5-year CDS spread. $M C G S p r e a d^{*}$ and $M C G D e v^{*}$ are the endogenous CDS-market systematic factors. $\Delta$ is the monthly change operator. The control variables are defined in Table 1. The standard errors of the coefficients re reported in ( ), where the robust variance-covariance is used following Hoechle (2007). ***, **,* stand for the statistical significance at the 1\%, 5\%, and $10 \%$ levels, respectively.

\begin{tabular}{|c|c|c|c|c|c|c|c|c|c|}
\hline & \multicolumn{9}{|c|}{$\Delta \log$ Spread } \\
\hline & Model 1 & Model 2 & Model 3 & Model 4 & Model 5 & Model 6 & Model 7 & Model 8 & Model 9 \\
\hline \multirow[t]{2}{*}{ Constant } & 0.006 & 0.005 & 0.006 & 0.002 & 0.001 & 0.001 & 0.002 & 0.001 & 0.000 \\
\hline & $(0.010)$ & $(0.011)$ & $(0.009)$ & $(0.007)$ & $(0.008)$ & $(0.007)$ & $(0.006)$ & $(0.005)$ & $(0.005)$ \\
\hline \multirow[t]{2}{*}{$\Delta \mathrm{CR}$} & -0.011 & & -0.008 & & & & -0.001 & -0.002 & -0.001 \\
\hline & $(0.009)$ & & $(0.009)$ & & & & $(0.007)$ & $(0.006)$ & $(0.007)$ \\
\hline \multirow[t]{2}{*}{$\Delta$ Size } & $-0.246^{* * *}$ & & $-0.244^{* * *}$ & & & & $-0.172^{* * *}$ & $-0.141^{* * *}$ & $-0.141^{* * *}$ \\
\hline & $(0.067)$ & & $(0.064)$ & & & & $(0.051)$ & $(0.050)$ & $(0.051)$ \\
\hline \multirow[t]{2}{*}{$\Delta \mathrm{Vol}$} & $0.509^{* * *}$ & & $0.463^{* * *}$ & & & & 0.042 & 0.036 & 0.037 \\
\hline & $(0.106)$ & & $(0.098)$ & & & & $(0.079)$ & $(0.061)$ & $(0.060)$ \\
\hline \multirow[t]{2}{*}{$\Delta \mathrm{Lev}$} & $0.489^{* * *}$ & & $0.470^{* * *}$ & & & & $0.300^{* * *}$ & $0.238^{* * *}$ & $0.237^{* * *}$ \\
\hline & $(0.053)$ & & $(0.052)$ & & & & $(0.035)$ & $(0.032)$ & $(0.033)$ \\
\hline \multirow[t]{2}{*}{$\Delta$ Recovery } & $-0.616^{* * *}$ & & $-0.654^{* * *}$ & & & & $-0.460^{* *}$ & $-0.451^{* *}$ & $-0.485^{* * *}$ \\
\hline & $(0.213)$ & & $(0.225)$ & & & & $(0.179)$ & $(0.183)$ & $(0.182)$ \\
\hline \multirow[t]{2}{*}{$\Delta \#$ Contributor } & & 0.001 & 0.001 & & & & 0.001 & 0.001 & 0.002 \\
\hline & & $(0.001)$ & $(0.001)$ & & & & $(0.001)$ & $(0.001)$ & $(0.001)$ \\
\hline \multirow[t]{2}{*}{$\Delta \mathrm{CDS}$ Slope } & & $6.280^{* *}$ & $6.455^{* * *}$ & & & & $5.770^{* * *}$ & $5.834^{* * *}$ & $5.838^{* * *}$ \\
\hline & & $(2.447)$ & $(2.344)$ & & & & $(2.039)$ & $(2.021)$ & $(2.021)$ \\
\hline \multirow[t]{2}{*}{$\Delta \mathrm{CDS}$ Amihud } & & $16.168^{* *}$ & 8.185 & & & & 5.962 & 6.038 & 7.000 \\
\hline & & $(7.325)$ & $(5.668)$ & & & & $(5.156)$ & $(5.020)$ & $(5.012)$ \\
\hline \multirow[t]{2}{*}{$\Delta \mathrm{CDS} H \mathrm{HL}$} & & $7.628^{* * *}$ & $6.453^{* * *}$ & & & & $5.591^{* * *}$ & $5.071^{* * *}$ & $5.085^{* * *}$ \\
\hline & & $(2.242)$ & $(1.841)$ & & & & $(1.621)$ & $(1.595)$ & $(1.572)$ \\
\hline \multirow[t]{2}{*}{$\Delta$ CDS Roll } & & -3.692 & -2.239 & & & & -1.815 & -1.412 & -1.415 \\
\hline & & $(5.498)$ & $(4.938)$ & & & & $(4.431)$ & $(4.334)$ & $(4.319)$ \\
\hline \multirow{2}{*}{$\Delta$ CDS Zeros } & & 0.032 & 0.021 & & & & 0.015 & 0.009 & 0.007 \\
\hline & & $(0.021)$ & $(0.018)$ & & & & $(0.019)$ & $(0.019)$ & $(0.018)$ \\
\hline \multirow[t]{2}{*}{$\Delta M C G S$ pread ${ }^{*}$} & & & & $0.545^{* * *}$ & & $0.431^{* * *}$ & $0.327^{* * *}$ & $0.195^{* * *}$ & $0.201^{* * *}$ \\
\hline & & & & $(0.046)$ & & $(0.060)$ & $(0.051)$ & $(0.055)$ & $(0.053)$ \\
\hline \multirow[t]{2}{*}{$\triangle M C G D e v^{*}$} & & & & & $1.468^{* * *}$ & $0.661^{* * *}$ & $0.709^{* * *}$ & $0.759^{* * *}$ & $0.733^{* * *}$ \\
\hline & & & & & $(0.173)$ & $(0.165)$ & $(0.148)$ & $(0.145)$ & $(0.142)$ \\
\hline \multirow{2}{*}{$\Delta \mathrm{VIX}$} & & & & & & & & 0.001 & 0.001 \\
\hline & & & & & & & & $(0.002)$ & $(0.002)$ \\
\hline \multirow[t]{2}{*}{$\Delta$ Treasury } & & & & & & & & -2.921 & -2.861 \\
\hline & & & & & & & & $(2.357)$ & $(2.598)$ \\
\hline \multirow[t]{2}{*}{$\Delta$ TermSpread } & & & & & & & & 0.228 & 0.604 \\
\hline & & & & & & & & $(2.161)$ & $(2.092)$ \\
\hline \multirow[t]{2}{*}{$\Delta$ DefaultSpread } & & & & & & & & $14.645^{* * *}$ & $12.992^{* * *}$ \\
\hline & & & & & & & & $(3.821)$ & $(4.967)$ \\
\hline \multirow[t]{2}{*}{$\Delta \mathrm{S} \& \mathrm{P} 500$} & & & & & & & & $-0.266^{*}$ & $-0.250^{*}$ \\
\hline & & & & & & & & $(0.141)$ & $(0.143)$ \\
\hline Adj. R-sqr & 0.114 & 0.060 & 0.157 & 0.208 & 0.139 & 0.227 & 0.278 & 0.299 & 0.261 \\
\hline $\mathrm{N}$ & 15811 & 15811 & 15811 & 15811 & 15811 & 15811 & 15811 & 15811 & 15811 \\
\hline Year FE & $\mathrm{NO}$ & NO & NO & NO & NO & NO & NO & NO & YES \\
\hline
\end{tabular}




\section{Table 8: Out-of-sample Performance}

This table reports the out-of-sample performance $\left(R_{O O S}^{2}\right)$ for the CDS systematic factors. The calculation of the $R_{O O S}^{2}$ is described in Equation (18), and the predictive systematic value is based on Equation 16 . Panel $\mathrm{A}, \mathrm{B}$, and $\mathrm{C}$ reports the $R_{O O S}^{2}$ for the 1-year, 2-year, and 3-year training period, respectively. Four benchmarks are used: (1) "Hist Avg" reports the results using the average over the training period; (2) "Past $1 \mathrm{Mth}$ " reports the results using the latest changes in log Spread; (3) "CG-Spread" reports the results using the latest $\log C$ GSpread; and (4) "Past 12Mth" reports the results using the average over 12 months. By Factor reports the out-of-sample for different regression specification of Equation (16). "MCGSpread* +MCGDev" uses both $\triangle M C G$ Spread $^{*}$ and $\triangle M C G D e v *$, while "MCGSpread* only" (or "MCGDev* only") uses only $\triangle M C G S p r e a d^{*}$ (or $\triangle M C G D e v^{*}$ ). "By Sector" reports the out-of-sample performance in different sectors. "Basic" sector includes firms from basic material, energy, utility, and not-defined; "Consumer" sector includes firms from consumer goods, consumer services, and healthcare; and "Industrial" sector includes firms from technology, telecommunication, and industrials.

\begin{tabular}{|c|c|c|c|c|}
\hline \multirow[b]{2}{*}{ Panel A: 1Y Training Period } & \multicolumn{4}{|c|}{$\Delta \log$ Spread Prediction } \\
\hline & Hist Avg & Past 1Mth & CG-Spread & Past 12Mth \\
\hline & (1) & $(2)$ & $(3)$ & (4) \\
\hline \multicolumn{5}{|l|}{ By Factor } \\
\hline MCGSpread ${ }^{*}+M C G D e v^{*}$ & 0.332 & 0.901 & 0.615 & \\
\hline MCGSpread* Only & 0.274 & 0.892 & 0.582 & \\
\hline$M C G D e v^{*}$ Only & 0.223 & 0.884 & 0.553 & \\
\hline \multicolumn{5}{|l|}{ By Sector } \\
\hline Basic & 0.343 & 0.854 & 0.627 & \\
\hline Consumer & 0.323 & 0.922 & 0.612 & \\
\hline Industry & 0.333 & 0.890 & 0.606 & \\
\hline
\end{tabular}

\begin{tabular}{|c|c|c|c|c|}
\hline \multicolumn{5}{|l|}{ Panel B: 2Y Training Period } \\
\hline MCGSpread + MCGDev ${ }^{*}$ & 0.180 & 0.869 & 0.538 & 0.197 \\
\hline MCGSpread* Only & 0.154 & 0.865 & 0.523 & 0.171 \\
\hline$M C G D e v^{*}$ Only & 0.119 & 0.859 & 0.503 & 0.136 \\
\hline \multicolumn{5}{|l|}{ By Sector } \\
\hline Basic & 0.185 & 0.822 & 0.542 & 0.206 \\
\hline Consumer & 0.178 & 0.899 & 0.540 & 0.191 \\
\hline Industry & 0.178 & 0.835 & 0.529 & 0.195 \\
\hline
\end{tabular}

Panel C: 3Y Training Period

\begin{tabular}{lllll}
\hline By Factor & & & & \\
MCGSpread $+M C G D e v^{*}$ & 0.130 & 0.854 & 0.519 & 0.170 \\
MCGSpread Only & 0.117 & 0.851 & 0.512 & 0.158 \\
$\quad$ MCGDev* Only & 0.079 & 0.845 & 0.491 & 0.121 \\
By Sector & & & & \\
Basic & 0.134 & 0.802 & 0.524 & 0.177 \\
Consumer & 0.126 & 0.889 & 0.522 & 0.166 \\
Industry & 0.130 & 0.812 & 0.510 & 0.167 \\
\hline
\end{tabular}


Table 9: CDS Systematic Factor Panel Regression: Weekly Changes

This table reports the panel regression results for CDS systematic factors. The sample period is from 2002 to 2011. log Spread is the logarithm of the observed 5-year CDS spread. $M C G$ Spread $^{*}$ and MCGDev* are the endogenous CDS-market systematic factors. $\Delta$ is the weekly change operator. The control variables are defined in Table 1. The standard errors of the coefficients re reported in ( ), where the robust variance-covariance is used following Hoechle (2007). ***, **, * stand for the statistical significance at the $1 \%, 5 \%$, and $10 \%$ levels, respectively.

\begin{tabular}{|c|c|c|c|c|c|c|c|c|c|}
\hline & \multicolumn{9}{|c|}{$\Delta \log$ Spread } \\
\hline & Model 1 & Model 2 & Model 3 & Model 4 & Model 5 & Model 6 & Model 7 & Model 8 & Model 9 \\
\hline \multirow[t]{2}{*}{ Constant } & 0.001 & 0.001 & 0.001 & 0.000 & 0.000 & 0.000 & 0.000 & 0.000 & 0.000 \\
\hline & $(0.002)$ & $(0.002)$ & $(0.002)$ & $(0.002)$ & $(0.002)$ & $(0.002)$ & $(0.002)$ & $(0.002)$ & $(0.001)$ \\
\hline \multirow[t]{2}{*}{$\Delta \mathrm{CR}$} & -0.004 & & -0.003 & & & & 0.005 & 0.006 & 0.006 \\
\hline & $(0.007)$ & & $(0.007)$ & & & & $(0.007)$ & $(0.007)$ & $(0.007)$ \\
\hline \multirow[t]{2}{*}{$\Delta$ Size } & 0.001 & & 0.003 & & & & 0.026 & 0.031 & 0.031 \\
\hline & $(0.054)$ & & $(0.052)$ & & & & $(0.051)$ & $(0.050)$ & $(0.051)$ \\
\hline \multirow[t]{2}{*}{$\Delta \mathrm{Vol}$} & $0.294^{* * *}$ & & $0.284^{* * *}$ & & & & -0.046 & $-0.097^{* *}$ & $-0.099^{* *}$ \\
\hline & $(0.054)$ & & $(0.052)$ & & & & $(0.047)$ & $(0.044)$ & $(0.044)$ \\
\hline \multirow[t]{2}{*}{$\Delta$ Lev } & $0.118^{* * *}$ & & $0.110^{* * *}$ & & & & 0.051 & 0.036 & 0.036 \\
\hline & $(0.034)$ & & $(0.032)$ & & & & $(0.031)$ & $(0.026)$ & $(0.026)$ \\
\hline \multirow[t]{2}{*}{$\Delta$ Recovery } & $-0.262^{*}$ & & $-0.274^{*}$ & & & & $-0.220^{* *}$ & $-0.223^{* *}$ & $-0.227^{* *}$ \\
\hline & $(0.137)$ & & $(0.140)$ & & & & $(0.108)$ & $(0.108)$ & (0.108) \\
\hline \multirow[t]{2}{*}{$\Delta \#$ Contributor } & & 0.000 & 0.000 & & & & 0.000 & 0.000 & 0.000 \\
\hline & & $(0.000)$ & $(0.000)$ & & & & $(0.000)$ & $(0.000)$ & $(0.000)$ \\
\hline \multirow[t]{2}{*}{$\Delta$ CDS Slope } & & $3.591^{* * *}$ & $3.620^{* * *}$ & & & & $3.506^{* * *}$ & $3.561^{* * *}$ & $3.566^{* * *}$ \\
\hline & & $(0.773)$ & $(0.765)$ & & & & $(0.709)$ & $(0.700)$ & $(0.702)$ \\
\hline \multirow[t]{2}{*}{$\Delta \mathrm{CDS}$ Amihud } & & $13.598^{* *}$ & $11.284^{*}$ & & & & $9.510^{*}$ & $9.633^{*}$ & $9.787^{*}$ \\
\hline & & $(6.561)$ & $(5.968)$ & & & & $(5.546)$ & $(5.608)$ & $(5.604)$ \\
\hline \multirow[t]{2}{*}{$\Delta \mathrm{CDS} H \mathrm{HL}$} & & $3.529^{* * *}$ & $3.443^{* * *}$ & & & & $3.007^{* * *}$ & $2.964^{* * *}$ & $2.955^{* * *}$ \\
\hline & & (1.079) & (1.064) & & & & $(0.981)$ & $(0.968)$ & $(0.958)$ \\
\hline \multirow[t]{2}{*}{$\Delta$ CDS Roll } & & -1.854 & -1.815 & & & & -1.807 & -1.746 & -1.763 \\
\hline & & $(3.119)$ & $(3.116)$ & & & & $(2.914)$ & $(2.849)$ & $(2.845)$ \\
\hline \multirow[t]{2}{*}{$\Delta \mathrm{CDS}$ Zeros } & & 0.023 & 0.019 & & & & 0.007 & 0.005 & 0.005 \\
\hline & & $(0.017)$ & $(0.016)$ & & & & $(0.016)$ & $(0.016)$ & $(0.016)$ \\
\hline \multirow[t]{2}{*}{$\Delta M C G S p r e a d^{*}$} & & & & $0.420^{* * *}$ & & $0.320^{* * *}$ & $0.315^{* * *}$ & $0.267^{* * *}$ & $0.261^{* * *}$ \\
\hline & & & & $(0.034)$ & & $(0.037)$ & $(0.036)$ & $(0.038)$ & $(0.038)$ \\
\hline \multirow[t]{2}{*}{$\triangle M C G D e v^{*}$} & & & & & $1.102^{* * *}$ & $0.609^{* * *}$ & $0.600^{* * *}$ & $0.639^{* * *}$ & $0.635^{* * *}$ \\
\hline & & & & & $(0.087)$ & $(0.088)$ & $(0.084)$ & $(0.083)$ & $(0.083)$ \\
\hline \multirow[t]{2}{*}{$\Delta \mathrm{VIX}$} & & & & & & & & -0.000 & -0.000 \\
\hline & & & & & & & & $(0.001)$ & $(0.001)$ \\
\hline \multirow[t]{2}{*}{$\Delta$ Treasury } & & & & & & & & -1.427 & -1.356 \\
\hline & & & & & & & & $(1.536)$ & $(1.568)$ \\
\hline \multirow[t]{2}{*}{$\Delta$ TermSpread } & & & & & & & & 0.006 & 0.016 \\
\hline & & & & & & & & $(1.466)$ & $(1.472)$ \\
\hline \multirow[t]{2}{*}{$\Delta$ DefaultSpread } & & & & & & & & $10.115^{* * *}$ & $9.370^{* *}$ \\
\hline & & & & & & & & $(3.906)$ & $(4.029)$ \\
\hline \multirow[t]{2}{*}{$\Delta \mathrm{S} \& \mathrm{P} 500$} & & & & & & & & 0.047 & 0.058 \\
\hline & & & & & & & & $(0.054)$ & $(0.055)$ \\
\hline Adj. R-sqr & 0.021 & 0.035 & 0.054 & 0.106 & 0.078 & 0.124 & 0.153 & 0.162 & 0.152 \\
\hline $\mathrm{N}$ & 69003 & 69003 & 69003 & 69003 & 69003 & 69003 & 69003 & 69003 & 69003 \\
\hline Year FE & NO & $\mathrm{NO}$ & NO & NO & $\mathrm{NO}$ & NO & NO & $\mathrm{NO}$ & YES \\
\hline
\end{tabular}


Table 10: CDS Systematic Factor Panel Regression: Adjusted Deviation Measure

This table reports the panel regression results for CDS systematic factors. The sample period is from 2002 to 2011. log Spread is the logarithm of the observed 5-year CDS spread. MCGSpread ${ }^{*}$ and $M \widetilde{C G D e v^{*}}$ are the endogenous CDS-market systematic factors, adjusted for the impact of individual credit and liquidity factors. $\Delta$ is the monthly change operator. The control variables are defined in Table 1. The standard errors of the coefficients re reported in ( ), where the robust variance-covariance is used following Hoechle (2007). $* * *, * *, *$ stand for the statistical significance at the $1 \%, 5 \%$, and $10 \%$ levels, respectively.

\begin{tabular}{|c|c|c|c|c|c|c|}
\hline & \multicolumn{6}{|c|}{$\Delta \log$ Spread } \\
\hline & Model 1 & Model 2 & Model 3 & Model 4 & Model 5 & Model 6 \\
\hline \multirow[t]{2}{*}{ Constant } & 0.002 & 0.000 & 0.000 & 0.001 & 0.001 & 0.000 \\
\hline & $(0.007)$ & $(0.007)$ & $(0.006)$ & $(0.006)$ & $(0.005)$ & $(0.005)$ \\
\hline \multirow[t]{2}{*}{$\Delta \mathrm{CR}$} & & & & -0.002 & -0.002 & -0.001 \\
\hline & & & & $(0.007)$ & $(0.006)$ & $(0.007)$ \\
\hline \multirow{2}{*}{$\Delta$ Size } & & & & $-0.163^{* * *}$ & $-0.134^{* * *}$ & $-0.136^{* * *}$ \\
\hline & & & & $(0.051)$ & $(0.049)$ & $(0.051)$ \\
\hline \multirow[t]{2}{*}{$\Delta \mathrm{Vol}$} & & & & 0.025 & 0.013 & 0.013 \\
\hline & & & & $(0.079)$ & $(0.062)$ & $(0.062)$ \\
\hline \multirow[t]{2}{*}{$\Delta \mathrm{Lev}$} & & & & $0.290 * * *$ & $0.234^{* * *}$ & $0.234^{* * *}$ \\
\hline & & & & $(0.035)$ & $(0.032)$ & $(0.033)$ \\
\hline \multirow[t]{2}{*}{$\Delta$ Recovery } & & & & $-0.495^{* * *}$ & $-0.491^{* * *}$ & $-0.523 * * *$ \\
\hline & & & & $(0.184)$ & $(0.188)$ & $(0.185)$ \\
\hline \multirow[t]{2}{*}{$\Delta \#$ Contributor } & & & & 0.001 & 0.001 & 0.001 \\
\hline & & & & $(0.001)$ & $(0.001)$ & $(0.001)$ \\
\hline \multirow[t]{2}{*}{$\Delta$ CDS Slope } & & & & $5.809 * * *$ & $5.892^{* * *}$ & $5.901 * * *$ \\
\hline & & & & $(2.061)$ & $(2.047)$ & $(2.046)$ \\
\hline \multirow[t]{2}{*}{$\triangle \mathrm{CDS}$ Amihud } & & & & 6.283 & 6.430 & 7.287 \\
\hline & & & & $(5.231)$ & $(5.083)$ & $(5.057)$ \\
\hline \multirow[t]{2}{*}{$\Delta \mathrm{CDS} H L$} & & & & $5.590 * * *$ & $5.077^{* * *}$ & $5.092^{* * *}$ \\
\hline & & & & $(1.621)$ & $(1.601)$ & $(1.578)$ \\
\hline \multirow[t]{2}{*}{$\Delta$ CDS Roll } & & & & -1.737 & -1.319 & -1.324 \\
\hline & & & & $(4.451)$ & $(4.362)$ & $(4.349)$ \\
\hline \multirow[t]{2}{*}{$\Delta$ CDS Zeros } & & & & 0.011 & 0.005 & 0.004 \\
\hline & & & & $(0.018)$ & $(0.018)$ & $(0.017)$ \\
\hline \multirow[t]{2}{*}{$\Delta M C G S p r e a d^{*}$} & $0.545^{* * *}$ & & $0.364^{* * *}$ & $0.267^{* * *}$ & $0.154^{* *}$ & $0.164^{* *}$ \\
\hline & $(0.046)$ & & $(0.072)$ & $(0.064)$ & $(0.066)$ & $(0.065)$ \\
\hline \multirow[t]{2}{*}{$\triangle M \overparen{C G D e v^{*}}$} & & $0.437^{* * *}$ & $0.208^{* * *}$ & $0.216^{* * *}$ & $0.220 * * *$ & $0.210^{* * *}$ \\
\hline & & $(0.044)$ & $(0.054)$ & $(0.049)$ & $(0.047)$ & $(0.048)$ \\
\hline \multirow[t]{2}{*}{$\Delta \mathrm{VIX}$} & & & & & 0.001 & 0.001 \\
\hline & & & & & $(0.002)$ & $(0.002)$ \\
\hline \multirow[t]{2}{*}{$\Delta$ Treasury } & & & & & -2.138 & -1.947 \\
\hline & & & & & $(2.466)$ & $(2.749)$ \\
\hline \multirow[t]{2}{*}{$\Delta$ TermSpread } & & & & & -0.298 & -0.081 \\
\hline & & & & & $(2.262)$ & $(2.243)$ \\
\hline \multirow[t]{2}{*}{$\Delta$ DefaultSpread } & & & & & $13.900^{* * *}$ & $12.348^{* *}$ \\
\hline & & & & & $(3.836)$ & $(4.894)$ \\
\hline \multirow[t]{2}{*}{$\Delta \mathrm{S} \& \mathrm{P} 500$} & & & & & -0.218 & -0.206 \\
\hline & & & & & $(0.143)$ & $(0.143)$ \\
\hline Adj. R-sqr & 0.208 & 0.185 & 0.227 & 0.277 & 0.295 & 0.256 \\
\hline $\mathrm{N}$ & 15811 & 15811 & 15811 & 15811 & 15811 & 15811 \\
\hline Year FE & $\mathrm{NO}$ & $\mathrm{NO}$ & $\mathrm{NO}$ & $\mathrm{NO}$ & $\mathrm{NO}$ & YES \\
\hline
\end{tabular}


Table 11: Correlation Matrix of Wavelets Decomposing CDS-Market Systematic Factors This table reports the correlation matrix of wavelets - Intrinsic Mode Functions (IMF) decomposing MCGSpread* and MCGDev*. The sample period is from 2002 to 2011.

\begin{tabular}{lrrrr}
\hline$\Delta$ MCGSpread & \multicolumn{4}{c}{$\Delta M C G$ Dev } \\
\cline { 2 - 5 } & IMF 1 & IMF 2 & IMF 3 & \multicolumn{1}{c}{ IMF 4 } \\
\hline IMF 1 & 0.47 & 0.05 & -0.03 & -0.05 \\
IMF 2 & 0.13 & 0.46 & 0.16 & 0.00 \\
IMF 3 & -0.08 & 0.08 & 0.09 & 0.44 \\
IMF 4 & 0.04 & -0.07 & 0.16 & 0.01 \\
IMF 5 & 0.00 & -0.17 & 0.06 & 0.76 \\
\hline
\end{tabular}


Figure 1: Time series plot for cross-sectional averages of CDS spread and its unadjusted components

This figure plots the time series of the cross-sectional average CDS spread (solid line), the average CreditGrades implied spread (dashed line), and the average absolute deviation between the two (dashed-dotted line) from 2002 to 2011.

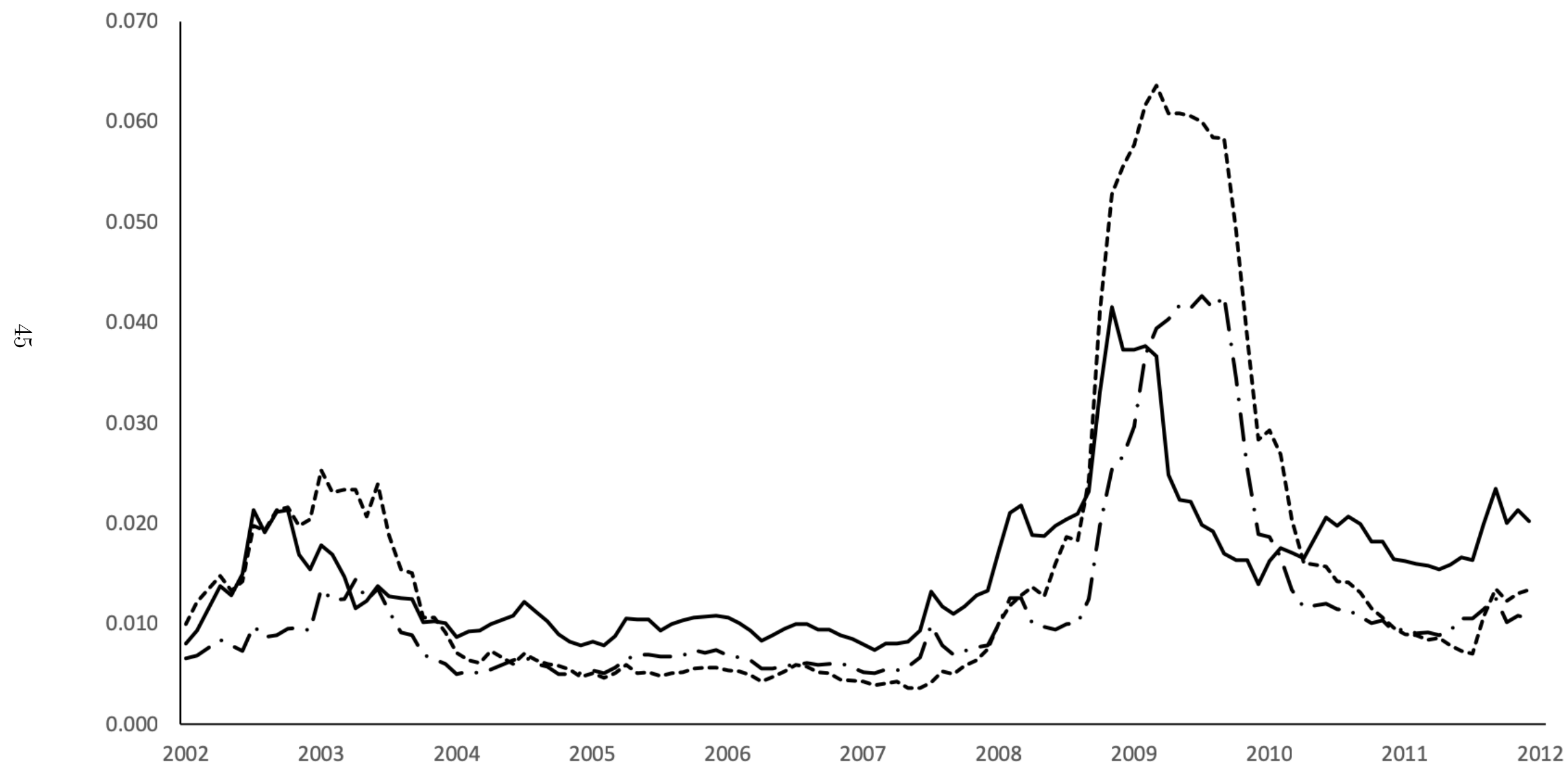

